\title{
Low-Dimensional Nanostructures for Electrochemical Energy Applications
}

\author{
Hsin-Yu Chen ${ }^{1,+}$, Yi-Hong Xiao ${ }^{1,+}$, Lin-Jiun Chen ${ }^{1,+}$, Chi-Ang Tseng ${ }^{2, *}$ and Chuan-Pei Lee ${ }^{1, *}$ (i) \\ 1 Department of Applied Physics and Chemistry, University of Taipei, Taipei 10048, Taiwan; \\ chy870128@gmail.com (H.-Y.C.); habitability2364@gmail.com (Y.-H.X.); mcgee0729@gmail.com (L.-J.C.) \\ 2 Department of Chemistry, National Taiwan University, Taipei 10617, Taiwan \\ * Correspondence: catseng919@ntu.edu.tw (C.-A.T.); CPLee@utaipei.edu.tw (C.-P.L.) \\ + These authors contributed equally.
}

Received: 28 July 2020; Accepted: 4 September 2020; Published: 11 September 2020

\begin{abstract}
Materials with different nanostructures can have diverse physical properties, and they exhibit unusual properties as compared to their bulk counterparts. Therefore, the structural control of desired nanomaterials is intensely attractive to many scientific applications. In this brief review, we mainly focus on reviewing our recent reports based on the materials of graphene and the transition metal chalcogenide, which have various low-dimensional nanostructures, in relation to the use of electrocatalysts in electrochemical energy applications; moreover, related literatures were also partially selected for discussion. In addition, future aspects of the nanostructure design related to the further enhancement of the performance of pertinent electrochemical energy devices will also be mentioned.
\end{abstract}

Keywords: diverse physical properties; electrochemical energy; graphene; nanostructures; low-dimensional structure; transition metal chalcogenide

\section{Introduction}

Since 2004, graphene has been unambiguously produced and identified, soon causing a boom in global research on two-dimensional materials [1]. Graphene shows great potential in electronics, composites, and catalysis due to its great conductivity, high electron mobility, and high surface area [2]. According to quantum mechanics, finite-size effects have been theoretically predicted and experimentally confirmed. Many studies have utilized a new type of graphene nanostructure, graphene quantum dots (GQDs), whose sizes are smaller than $100 \mathrm{~nm}$ [3]. GQDs exhibit great crystallinity, preserving the promising chemical and physical properties of graphene. A recent report revealed that the addition of GQD in counter electrodes (CEs) increased the efficiency in dye-sensitized solar cells (DSSCs) due to the improvement of the catalytic activity and the increase of the electrocatalytic surface area. Owing to quantum confinement and edge effects, GQDs have generated great interest in photovoltaics and light-emitting diodes (LED) applications [4]. On the other hand, 3-dimensional (3D) graphene materials such as graphene hollow balls have recently been produced for the improvement of the electrocatalytic activity and surface area in electrocatalysis applications [5]. Transition metal dichalcogenides (TMDCs), two-dimensional layered semiconductor materials with a chemical bond within an in-plane structure and an attraction by Van der Waals force between layers, have attracted much attention in recent years. For example, molybdenum disulfide $\left(\mathrm{MoS}_{2}\right)$, tungsten disulfide $\left(\mathrm{WS}_{2}\right)$, molybdenum diselenide (MoSe $)$, and tungsten diselenide $\left(\mathrm{WSe}_{2}\right)$ are noted for their low cost, abundance and easy processing. 1-dimensional (1D) TMDCs, such as nanowires (NWs), nanotubes (NTs), and nanoneedles (NDs), play a significant role in nanoscale electronic or photoelectronic devices due to their fast charge transporting property [6-8]. TMDCs have been investigated as 
potential materials to replace platinum $(\mathrm{Pt})$ as electrocatalysts in hydrogen evolution reactions (HERs) because they are earth-abundant and possess excellent electrochemical properties [9-11]. Meanwhile, 2-dimensional (2D) materials with a high surface area and high conductivity have also attracted much attention in recent years. There is a transformation from indirect bandgap to direct bandgap when $2 \mathrm{D}$ materials are stripped from bulk ones to monolayers [12]. Studies have shown that 2D materials show promise in catalysis and energy storage because of their unique properties and structure [13,14]. In this article, the different dimensions of graphene and TMDC materials in electrochemical applications will be briefly reviewed.

\section{Zero-Dimensional Graphene Material for the Counter Electrode of Dye-Sensitized Solar Cells}

\subsection{Graphene Quantum Dot-Doped Polypyrrole}

Contrary to carbon nanotubes and graphene, GQDs exhibit much smaller sizes while retaining their graphitic nature. In Chen and his coworkers' research [15], GQDs were prepared with a chemical oxidation approach and used to dope in polypyrrole (PPy) film through the electrochemical codeposition method. The transmission electron microscope (TEM) image in Figure 1a shows that the GQDs show quite a uniform size of around $10 \mathrm{~nm}$. The atomic force microscope (AFM) image, along with the corresponding height profile (as shown in Figure 1b), revealed that the GQDs exhibited an average height of $0.8 \mathrm{~nm}$, indicating the monolayer structure. The morphologies of GQD-doped PPy and bare PPy films are observed by scanning electron microscope (SEM), as shown in Figure 2. The GQD-doped PPy film exhibits a porous structure, while the plain PPy shows quite a dense structure. If there were more GQDs in the PPy film, the pertinent counter electrode would possess better electrode kinetics due to the increase of electrocatalytic actives. As shown in Figure 3a, the cyclic voltammetry (CV) curves demonstrate a typical pair of adsorption peaks $(\sim 0.4 \mathrm{~V} \mathrm{vs} . \mathrm{Ag} / \mathrm{AgCl})$ and a pair of $\mathrm{I}^{-} / \mathrm{I}_{3}{ }^{-}$ redox reactions at approximately -0.4 and $0.75 \mathrm{~V}$, respectively, similarly to the previous report [16]. The more positive potential of the reduction peak and higher current density of the GQD-doped PPy electrode reveal that it performs a higher electrocatalytic activity and more reaction actives for the $\mathrm{I}_{3}{ }^{-}$ ions reduction. Figure $3 \mathrm{~b}$ shows the Nyquist plots of GQD-doped PPy and PPy electrodes, measured by electrochemical impedance spectroscopy (EIS). The semicircle diameter of GQD-doped PPy is smaller than that of PPy, indicating that the charge-transfer resistance $\left(R_{\mathrm{ct}}\right)$ of GQD-doped PPy is lower than that of PPy. These results imply that GQDs can improve the charge transfer rate in the cathodic reaction process.
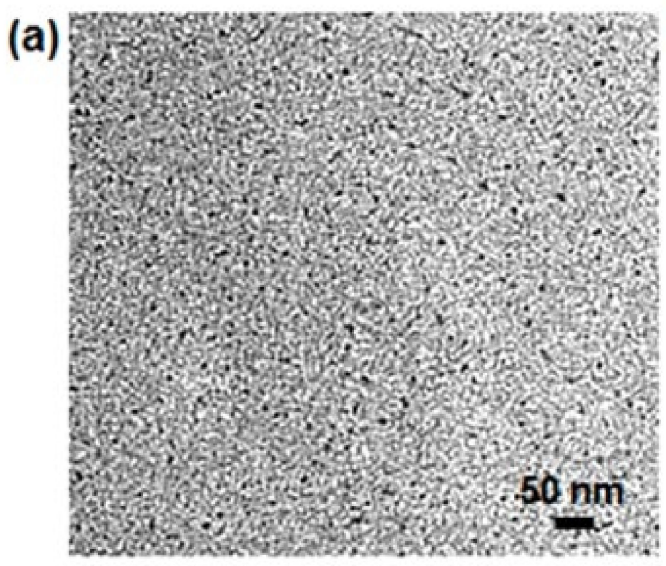

(b)

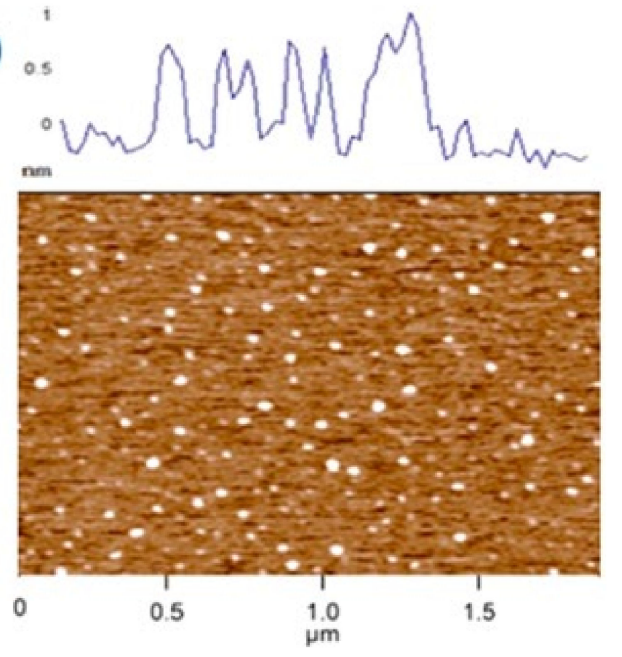

Figure 1. The sample of GQDs: (a) The TEM image and (b) AFM image with the corresponding height profile [15]. GQDs: graphene quantum dots; TEM: transmission electron microscope; AFM: atomic force microscope. 

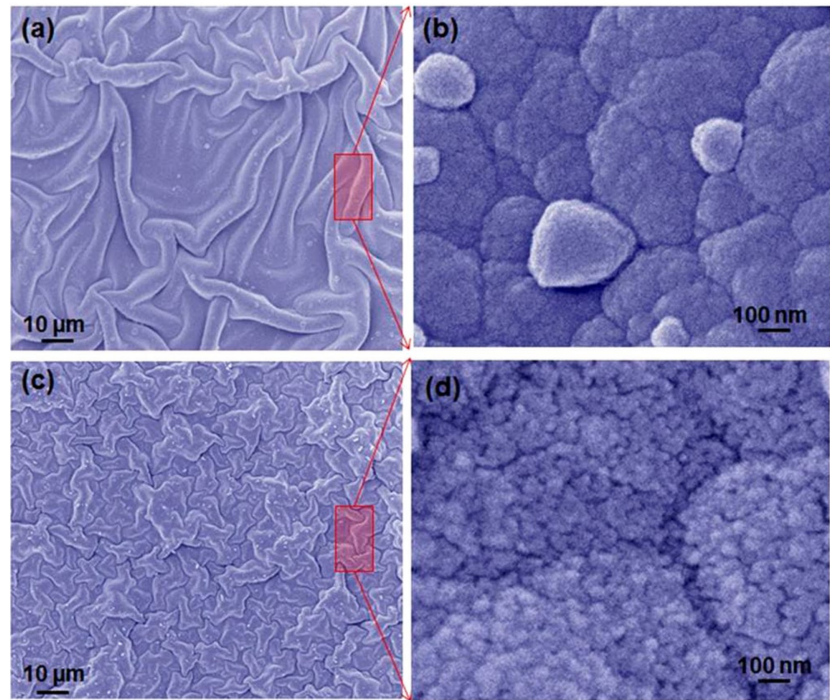

Figure 2. The high and low magnifications of SEM images of $(\mathbf{a}, \mathbf{c})$ PPy and $(\mathbf{b}, \mathbf{d}) 10 \%$ GQD-doped PPy [15]. SEM: scanning electron microscope; PPy: polypyrrole; GQD: graphene quantum dot.
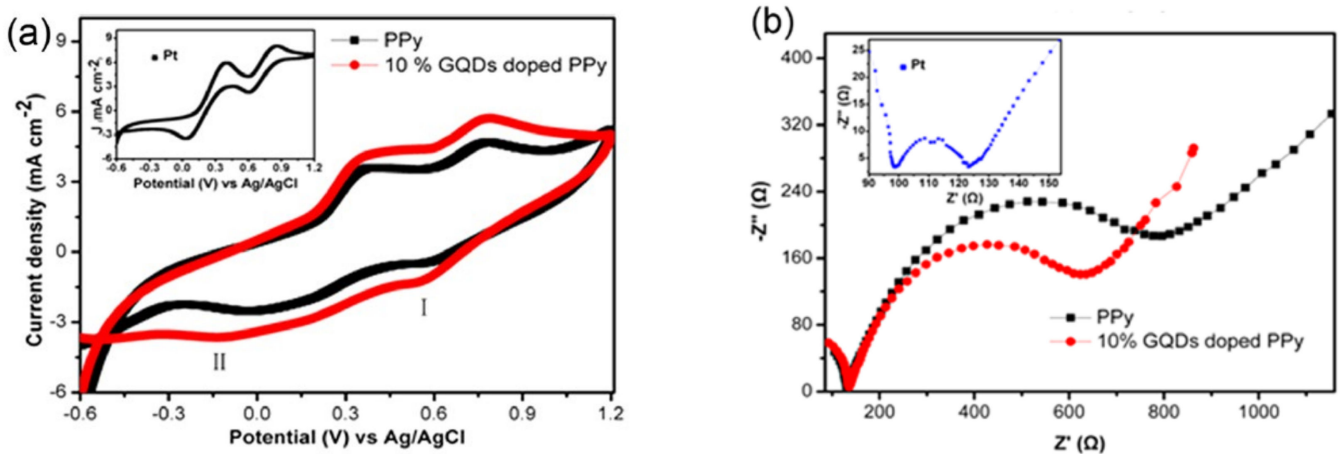

Figure 3. (a) CV curves of plain PPy and GQD-doped PPy CE. The inset is the CV curve of the Pt CE toward the $\mathrm{I}^{-} / \mathrm{I}_{3}{ }^{-}$redox reaction. (b) Nyquist plots of bare PPy and GQD-doped PPy CEs. The inset shows the Nyquist plot of Pt CE [15]. CV: cyclic voltammetry; PPy: polypyrrole; GQD: graphene quantum dot; CE: counter electrode.

DSSC with 10\% GQD-doped PPy CEs achieves the highest power conversion efficiency (PCE) at $5.27 \%$, which is around $20 \%$ higher than that of DSSC with bare PPy $(4.46 \%)$ and is comparable to that of DSSC with platinum (Pt) (see Table 1). The GQD-doped PPy CE provides a promising candidate to replace Pt as a cheap CE for high-performance DSSC.

Table 1. Performance parameters of DSSCs with different amounts of GQD-doped PPy CEs under AM1.5 G illumination [15]. DSSCs: dye-sensitized solar cells; GQD: graphene quantum dot; PPy: polypyrrole; CE: counter electrode; AM1.5 G: the air mass is 1.5 (where the sun is about $41^{\circ}$ above the horizon); $V / V$ : volume percentage concentration; PCE: power conversion efficiency; $V_{\text {oc: }}$ open-circuit voltage; $I_{\mathrm{Sc}}$ : short cut current; FF: fill factor.

\begin{tabular}{ccccc}
\hline GQD Ratio $(\boldsymbol{V} / \mathbf{V}) \mathbf{( \% )}$ & PCE $(\%)$ & $\boldsymbol{V}_{\mathbf{~ o c}}(\mathbf{V})$ & $\boldsymbol{I}_{\mathbf{s c}}\left(\mathbf{m A ~ c m}^{-\mathbf{2}}\right)$ & FF $(\%)$ \\
\hline 0 & 4.46 & 0.72 & 12.83 & 48.60 \\
3 & 4.89 & 0.74 & 13.81 & 47.90 \\
10 & 5.27 & 0.72 & 14.36 & 50.80 \\
15 & 5.00 & 0.73 & 13.80 & 49.80 \\
20 & 4.94 & 0.73 & 12.23 & 55.60 \\
25 & 4.67 & 0.70 & 12.07 & 55.60 \\
30 & 4.62 & 0.71 & 11.41 & 57.30 \\
$\mathrm{Pt}$ & 6.02 & 0.70 & 12.81 & 67.50 \\
\hline
\end{tabular}




\subsection{Graphene Quantum Dot-Decorated Strontium Ruthenate $\left(\mathrm{SrRuO} \mathrm{O}_{3}\right)$ Mesoporous Film}

Liu et al. [17] found that, via a dipping technique, the combination of strontium ruthenate $\left(\mathrm{SrRuO}_{3}\right.$, $\mathrm{SRO}$ ) nanoparticles and GQDs yields a compelling advantage in terms of improving the conductivity and the catalytic activity (Figure 4) [17]. GQDs with good conductivity are responsible for connecting $\mathrm{SrRuO}_{3}$ nanoparticles and promoting the formation of a conductive network for the SRO-GQD CEs, which show a resistivity of $4.5 \times 10^{-2}-5.9 \times 10^{-2} \Omega \mathrm{cm}$ via a four-probe measurement. The synergic effect of $\mathrm{SrRuO}_{3}$ and GQDs provides multiple benefits in driving ion spread and collecting electrons from the external circuit, as well as in accelerating electron transfer to catalytic sites, thus achieving a high electrocatalytic capability towards the $\mathrm{I}^{-} / \mathrm{I}_{3}{ }^{-}$redox reaction. Consequently, this results in a great PCE of DSSC devices with SRO-GQD CEs (8.05\%) (see Figure 5), which is much higher than for DSSCs with other kinds of GQD-based composite CEs in the literature [18].

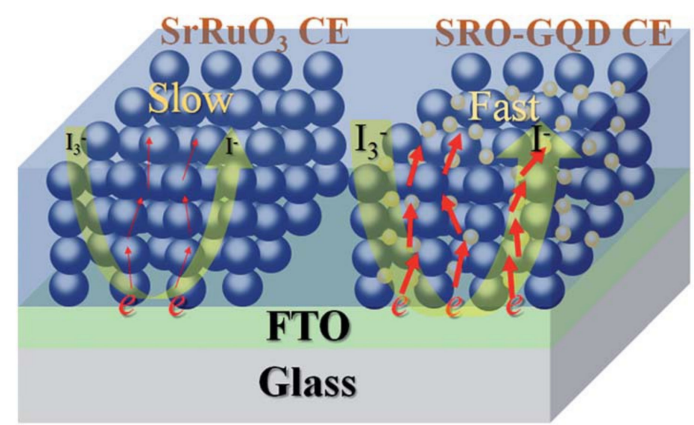

Figure 4. The schematic diagram of the electrolyte regeneration reaction for $\mathrm{SrRuO}_{3}$ and SRO-GQD hybrid CEs [17]. $\mathrm{SrRuO}_{3}$ : Strontium Ruthenate; SRO-GQD: Strontium Ruthenate-graphene quantum dot; CEs: counter electrodes; FTO: Fluorine-doped tin oxide.

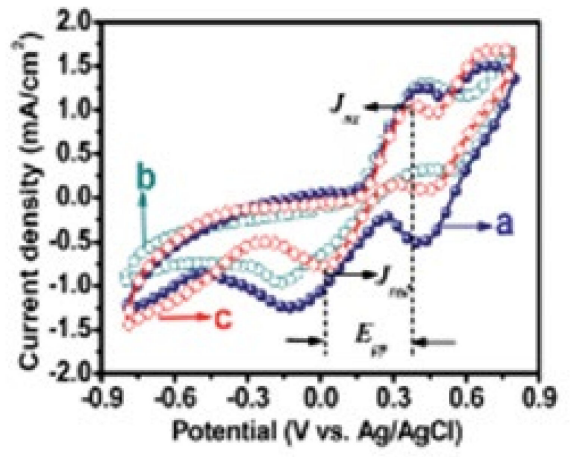

(a)

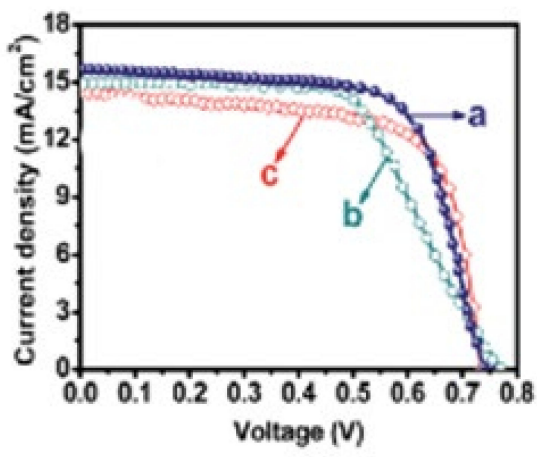

(b)

Figure 5. (a) The cyclic voltammograms of different CEs ((line a) SRO-GQD, (line b) $\mathrm{SrRuO}_{3}$ and (line c) $\mathrm{Pt}$ ) recorded at a scan rate of $50 \mathrm{mV} \mathrm{s}^{-1}$ in an acetonitrile solution of $10 \mathrm{mM} \mathrm{LiI}, 1 \mathrm{mM}$ $\mathrm{I}_{2}$ and $0.1 \mathrm{M} \mathrm{LiClO}_{4}$. (b) $\mathrm{J}-\mathrm{V}$ characteristics of the DSSCs using different CEs measured under AM 1.5 simulated solar illumination $\left(100 \mathrm{~mW} \mathrm{~cm}^{-2}\right)$ [17]. CEs: counter electrodes; SRO-GQD: Strontium Ruthenate-graphene quantum dot; $\mathrm{SrRuO}_{3}$ : Strontium Ruthenate; J-V: photocurrent density-photovoltage; DSSCs: dye-sensitized solar cells; AM: air mass.

According to the Nyquist plots shown in Figure 6a, one can obviously see that the semicircle diameter of the SRO-GQD CE is smaller than that of the $\mathrm{SrRuO}_{3} \mathrm{CE}$, suggesting a lower $R_{\mathrm{ct}}$ of SRO-GQD than that of $\mathrm{SrRuO}_{3}$. The Tafel polarization curves shown in Figure $5 \mathrm{~b}$ characterize the catalytic abilities of $\mathrm{SrRuO}_{3}$ and SRO-GQD CEs towards the $\mathrm{I}^{-} / \mathrm{I}_{3}{ }^{-}$redox reaction. The exchange current density $\left(J_{0}\right)$ and the limiting diffusion current density $\left(J_{\text {lim }}\right)$ obtained from the Tafel curves are closely related to the catalytic activity of the CEs. Compared with $\mathrm{SrRuO}_{3}, \mathrm{SRO}-\mathrm{GQD}$ possesses a higher $\mathrm{J}_{0}$ due to a larger slope for the anodic or cathodic branches, revealing a higher electrocatalytic 
activity on the $\mathrm{I}^{-} / \mathrm{I}_{3}{ }^{-}$redox reaction, which is in good correlation with the trends derived from the $\mathrm{CV}$ and EIS analyses.

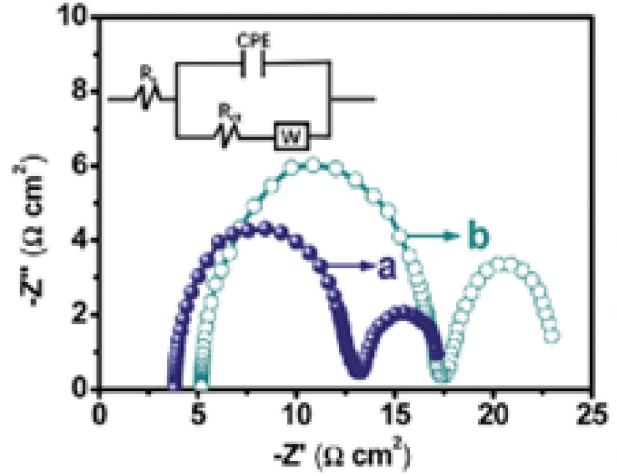

(a)

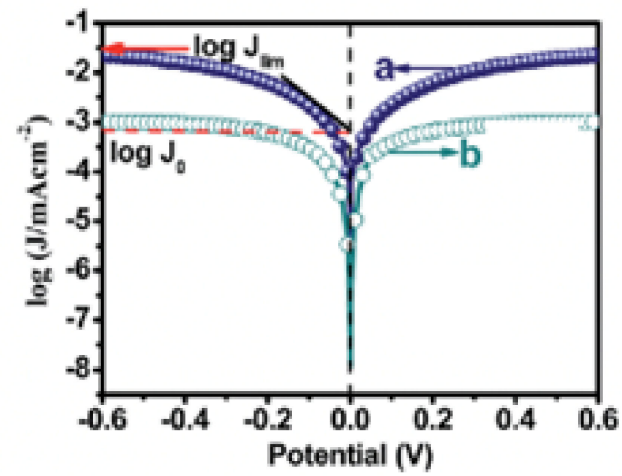

(b)

Figure 6. (a) Nyquist plots derived from the EIS of the symmetrical dummy cells with (line a) SRO-GQD and (line b) $\mathrm{SrRuO}_{3} \mathrm{CEs}$. The equivalent circuit diagram used for the fitting of the Nyquist plots is inserted as the inset. (b) Tafel polarization curves of the symmetrical dummy cells [17]. EIS: electrochemical impedance spectroscopy; SRO-GQD: Strontium Ruthenate-graphene quantum dot; $\mathrm{SrRuO}_{3}$ : Strontium Ruthenate; CEs: counter electrodes.

\subsection{Graphene Dots (GDs)/poly(3,4-Ethylene Dioxythiophene):poly(4-Styrene Sulfonate) (PEDOT:PSS) Composite Film}

A water-dispersible conducting polymer, PEDOT:PSS, has attracted much attention as the catalytic CE of DSSCs, mainly due to its outstanding advantage of having aqueous solution processability [19]. However, pristine PEDOT:PSS films are limited by a low conductivity and poor electrocatalytic activity in the reduction of $\mathrm{I}_{3}{ }^{-}$, due to the nonconductive counter anion of PSS, which blocks the electron transporting path inside the film. In recent research [20], the conductivity and catalytic surface areas could be improved by doping carbon materials, especially GDs with high active sites, into PEDOT:PSS films. Figure 7a shows the TEM image of the monodispersed GDs, which exhibit uniform diameters of $3.5 \mathrm{~nm}$. As shown in the inset of Figure 7a, the high-resolution TEM (HRTEM) image indicates a high crystallinity of GQDs with a lattice parameter of $0.246 \mathrm{~nm}$ that corresponds to the (1120) lattice fringes of graphene. The AFM image of monodispersed GDs is shown in Figure 7b. The average height of these GDs is $2.90 \mathrm{~nm}$, as shown in the inset of Figure $7 \mathrm{~b}$.
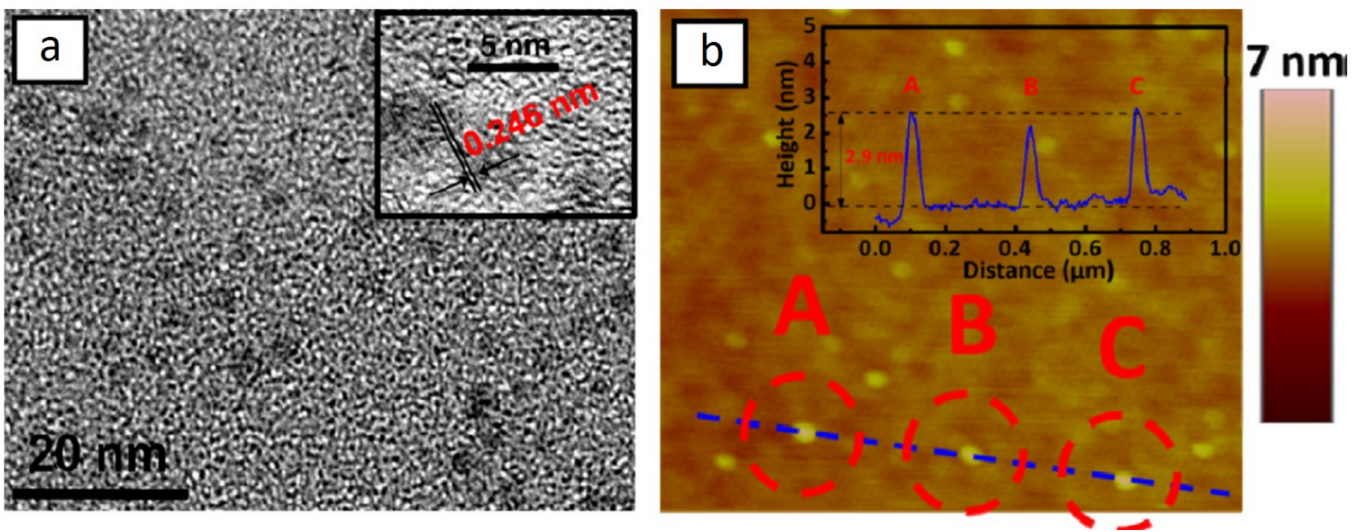

Figure 7. (a) TEM image of GQDs and its corresponding HRTEM image (inset). (b) AFM image of the GDs and its corresponding height profile (inset) [20]. TEM: transmission electron microscope; GQDs: graphene quantum dots; HRTEM: high resolution transmission electron microscope; AFM: atomic force microscope; GDs: graphene dots. 
As shown in Figure 8, the thickness of PEDOT:PSS and GD-PEDOT:PSS films are almost similar (around $6.3 \mu \mathrm{m}$ ); the PEDOT:PSS film exhibits a flat and smooth morphology, while the GD-PEDOT:PSS film displays a rough morphology consisting of irregular island-like structures. The high superficial roughness is predicted to enhance the electrocatalytic activity for the $\mathrm{I}^{-} / \mathrm{I}_{3}{ }^{-}$redox couple, as well as to reduce the $R_{\mathrm{ct}}$ at the CE/electrolyte interface. Moreover, the sheet resistance of the GDs-PEDOT:PSS film $\left(1.5 \times 10^{-4} \Omega \mathrm{cm}\right)$ was found to be lower when compared to that of the PEDOT:PSS film $\left(9.6 \times 10^{-4} \Omega \mathrm{cm}\right)$. We found that GD-PEDOT:PSS CEs possess a higher cathodic current density and smaller redox peaks separation $(347 \mathrm{mV}$ ) (Figure $9 \mathrm{a}$ and Table 2), which can be attributed to its larger surface area and the faster charge transfer kinetics at the $\mathrm{CE} /$ electrolyte interface. The photocurrent density versus voltage $(\mathrm{J}-\mathrm{V})$ characteristics of the DSSCs with PEDOT:PSS CEs and GD-PEDOT:PSS CEs are shown in Figure 9b, and the corresponding photovoltaic parameters are listed in Table 3. The cell with GD-PEDOT:PSS CEs shows the best performance, with a cell efficiency of $7.36 \%$, which is much higher than that of the cell with PEDOT:PSS CEs (5.14\%) and close to that of the cell with sputtered Pt CEs $(8.46 \%)$. Compared to the photocurrent density $\left(J_{S C}\right)$ of the DSSC with flat PEDOT:PSS films as CEs, the DSSC with GD-PEDOT:PSS CEs performs a high $J_{S C}$, which is attributed to more electrocatalytically active sites on the rough surface of GD-PEDOT:PSS films for the reduction of triiodide ions. A faster diffusion of the redox couple is expected in the electrolyte of the DSSC with GD-PEDOT:PSS CEs due to the faster reduction of $\mathrm{I}_{3}{ }^{-}$ions at the $\mathrm{CE}$ of the cell, which in turn can lead to faster electron transfer kinetics and a higher fill factor (FF) for the cell (0.70), when compared to that of the cell with PEDOT:PSS CEs $(0.60)$. The $R_{\text {ct }}$ property at the CE/electrolyte interface was performed by EIS. The symmetric sandwich-type cells with PEDOT:PSS and GD-PEDOT:PSS electrodes possess $R_{\mathrm{ct}}$ values of 10.38 and $7.92 \Omega \mathrm{cm}^{2}$, respectively (Figure 9c). The results show that GD-PEDOT:PSS catalytic films can effectively catalyze the reduction of $\mathrm{I}_{3}{ }^{-}$ions to $\mathrm{I}^{-}$ions due to low charge transfer resistances, leading to a high performance of the DSSC with GD-PEDOT:PSS CEs.
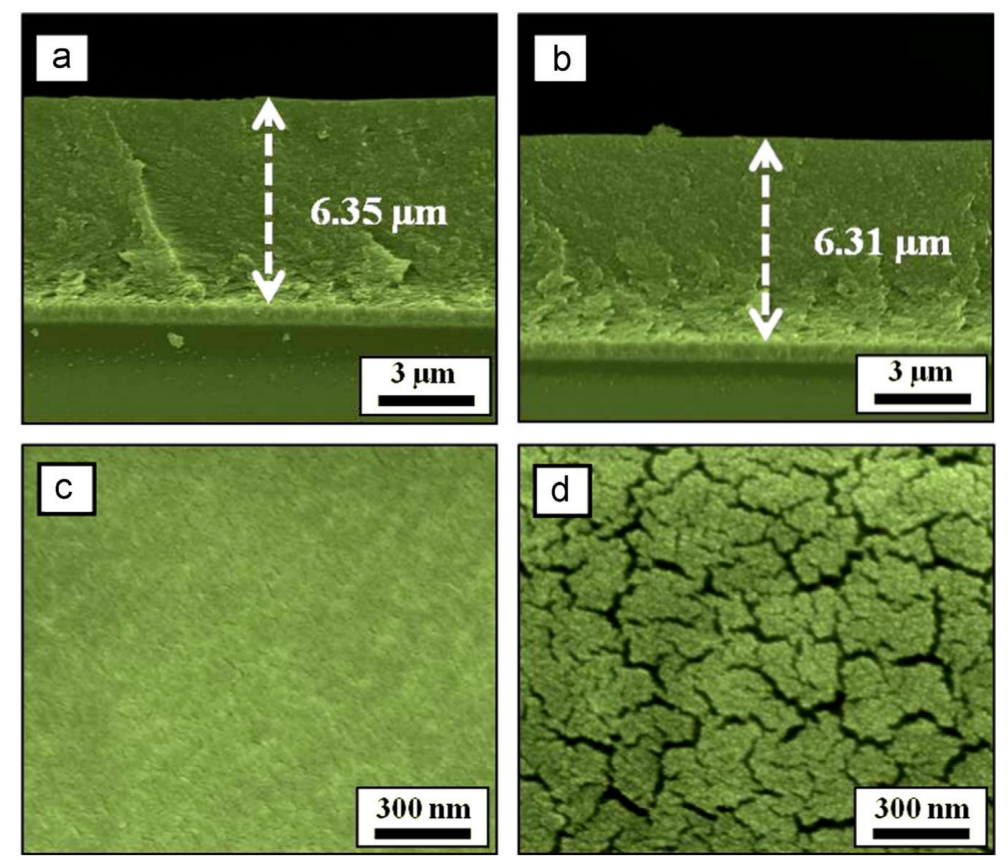

Figure 8. Cross-sectional SEM images of (a) PEDOT:PSS and (b) GD-PEDOT:PSS films. Corresponding top-view SEM images of (c) PEDOT:PSS and (d) GD-PEDOT:PSS films [20]. SEM: scanning electron microscope; PEDOT:PSS: poly(3,4-ethylene dioxythiophene):poly(4-styrene sulfonate); GD-PEDOT:PSS: graphene dot-poly(3,4-ethylene dioxythiophene):poly(4-styrene sulfonate). 

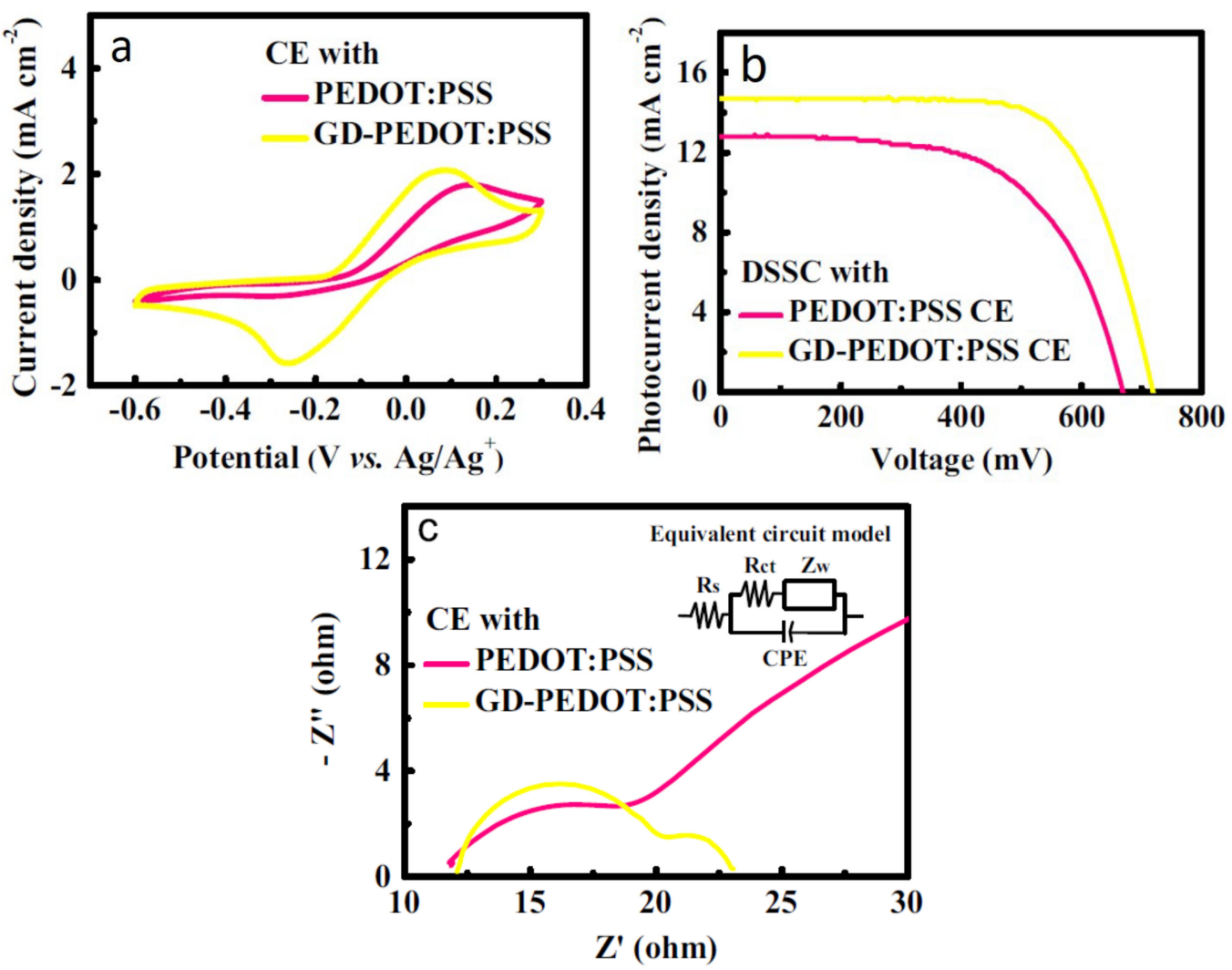

Figure 9. (a) The J-V curves of the DSSCs with PEDOT:PSS and GD-PEDOT:PSS CEs measured at $100 \mathrm{~mW} \mathrm{~cm}^{-2}$ (AM $1.5 \mathrm{G}$ ). (b) The CV curves of the CEs with PEDOT:PSS and GD-PEDOT:PSS films. (c) Nyquist plots of the symmetric sandwich-type cells with PEDOT:PSS and GD-PEDOT:PSS CEs obtained at a zero bias potential. The inset shows the equivalent circuit [20]. J-V: Photocurrent density-photovoltage; DSSCs: dye-sensitized solar cells; PEDOT:PSS: poly(3,4-ethylene dioxythiophene):poly(4-styrene sulfonate); GD-PEDOT:PSS: graphene dot-poly(3,4-ethylene dioxythiophene):poly(4-styrene sulfonate); CEs: counter electrodes; AM1.5 G: the air mass is 1.5 (where the sun is about $41^{\circ}$ above the horizon); CV: cyclic voltammetry.

Table 2. Electrochemical parameters for different counter electrodes [20].

\begin{tabular}{|c|c|c|c|}
\hline CE with & Cathodic Current Density ${ }^{a}\left(\mathrm{~mA} \mathrm{~cm}^{-2}\right)$ & $\begin{array}{l}\Delta E_{\mathrm{p}}{ }^{\mathrm{a}} \\
(\mathrm{mV})\end{array}$ & $R_{\mathrm{ct}}^{\mathrm{b}}(\mathrm{ohm})$ \\
\hline PEDOT:PSS & -0.39 & 436 & 10.38 \\
\hline GD-PEDOT:PSS & -1.58 & 347 & 7.92 \\
\hline
\end{tabular}

a The values are obtained from $\mathrm{CV}$; ${ }^{\mathrm{b}}$ The values are obtained from EIS; CEs: counter electrodes; PEDOT:PSS: poly(3,4-ethylene dioxythiophene):poly(4-styrene sulfonate); GD-PEDOT:PSS: graphene dot-poly(3,4-ethylene dioxythiophene):poly(4-styrene sulfonate); $\Delta E_{\mathrm{p}}$ : peak separation. $R_{\mathrm{ct}}$ : charge-transfer resistance.

Table 3. Photovoltaic parameters of the DSSCs with PEDOT:PSS and with GD-PEDOT:PSS counter electrodes [20].

\begin{tabular}{ccccc}
\hline DSSC with & $\eta(\mathbf{\%})$ & $\boldsymbol{V}_{\mathbf{o c}}(\mathbf{m V})$ & $J_{\mathbf{s c}}\left(\mathbf{m A ~ c m} \mathbf{~ c m}^{-2}\right)$ & FF \\
\hline PEDOT:PSS CE & 5.14 & 668 & 12.82 & 0.60 \\
GD-PEDOT:PSS CE & 7.36 & 718 & 14.70 & 0.70 \\
\hline
\end{tabular}

DSSCs: dye-sensitized solar cells; PEDOT:PSS: poly(3,4-ethylene dioxythiophene):poly(4-styrene sulfonate); GD-PEDOT:PSS: graphene dot-poly(3,4-ethylene dioxythiophene):poly(4-styrene sulfonate); CE: counter electrode; $\eta$ : the cell efficiency of the DSSC; $V_{\mathrm{oc}}$ : open-circuit voltage; $J_{\mathrm{sc}}$ : photocurrent density; FF: fill factor. 
Furthermore, there are several studies that focus on $\mathrm{MoS}_{2}$ quantum dots (MSQDs) in relation to the hydrogen evolution reaction (HER) and oxygen evolution reaction (OER). Density functional theory studies show that MSQDs are reactive and that the vacancies at the edges can promote the reaction, which indicates that defects at the edges are efficient for the OER and HER. However, the synthesis of MSQDs is usually done in the presence of carbon solvents, which results in the formation of unavoidable carbon QDs (CQDs), which would interfere with the properties and performance of MSQDs. The report shows that applying the one-step methods can avoid the formation of unwanted carbon quantum dots (CQDs) and enhance the OER activity of MSQDs [21]. MSQD is also a good material for the HER reaction. The monolayer MSQDs exhibit superior HER catalytic activities with a low overpotential of approximately $120 \mathrm{mV}$ and a relatively small Tafel slope of $69 \mathrm{mV} \mathrm{dec}^{-1}$. Both the unique structure and the large amounts of exposed active edge sites make monolayer MSQDs promising HER electrocatalysts [22].

\section{One-Dimensional Materials for Hydrogen Evolution Reaction (HER)}

\subsection{One-Dimensional Nanowire}

In 2011, Chen et al. [23] successfully synthesized vertically oriented core-shell molybdenum(VI) oxide-molybdenum disulfide $\left(\mathrm{MoO}_{3}-\mathrm{MoS}_{2}\right)$ nanowires [23]. They used low-temperature sulfidization to obtain the best properties of each material. There are no apparent changes in the nanowire morphology before (Figure 10a) or after (Figure 10b) sulfidization at $200{ }^{\circ} \mathrm{C}$. Some nanowires exhibit sharper tips and have a more grass-like morphology at $300{ }^{\circ} \mathrm{C}$ or higher sulfidization temperatures (Figure 10b-f). The X-ray diffraction (XRD) spectra shown in Figure 11 indicate that, when sulfidized at $300{ }^{\circ} \mathrm{C}$ and above, all peaks corresponding to the $\mathrm{MoO}_{3}$ disappear, which means a lack of long-range order of the phase. Combining a conductive core comprised of substoichiometric $\mathrm{MoO}_{3}$ with a conformal $\mathrm{MoS}_{2}$ shell, they have created a high-aspect ratio structure that can enhance charge transports over large distances with a high catalytic activity and stability in acidic solvents. Electrochemical measurements of the core-shell $\mathrm{MoO}_{3}-\mathrm{MoS}_{2}$ nanowires are shown in Figure 12. Apparently, sulfidization at $300^{\circ} \mathrm{C}$ decreases the HER activity. However, the nanowires with sulfidization at $200^{\circ} \mathrm{C}$ demonstrate a lower overpotential of approximately 150-200 $\mathrm{mV}$. A Tafel plot was constructed to gain more insight into the activity of nanowires: the Tafel slope was 50-60 mV/decade near the onset of the current at $200 \mathrm{mV}$. Compared with other non-noble materials, the core-shell $\mathrm{MoO}_{3}-\mathrm{MoS}_{2}$ nanowire (denoted " $\mathrm{MoS}_{2}$ " in Figure 12d) is highly active, especially at higher current densities $\left(>10 \mathrm{~mA} \mathrm{~cm}^{-2}\right)$.

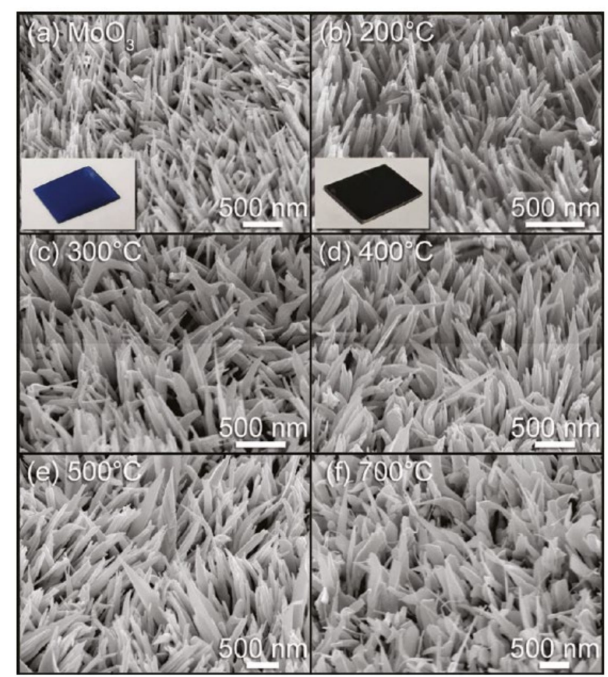

Figure 10. External morphology of (a) $\mathrm{MoO}_{3}$ nanowires, and (b-f) $\mathrm{MoO}_{3}$ nanowire sulfidized at different temperatures [23]. 


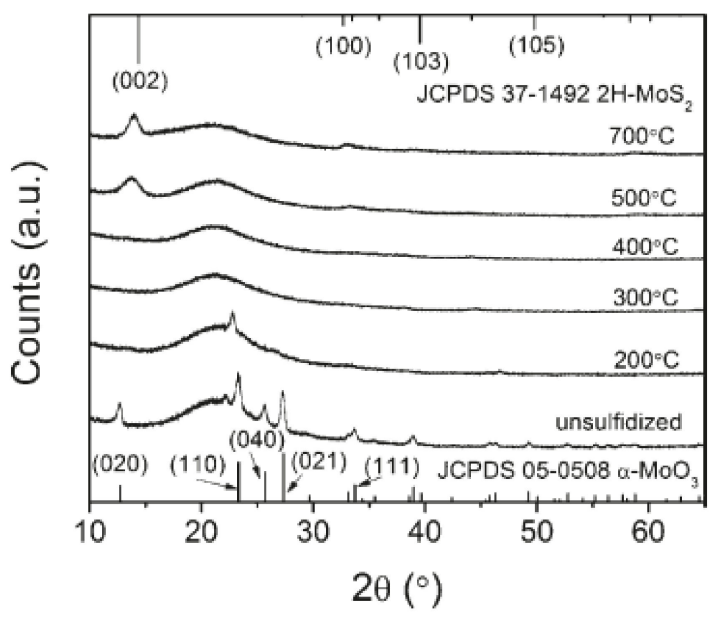

Figure 11. XRD spectra of $\mathrm{MoO}_{3}-\mathrm{MoS}_{2}$ nanowires on amorphous quartz sulfidized at various temperatures [23]. XRD: X-ray diffraction.
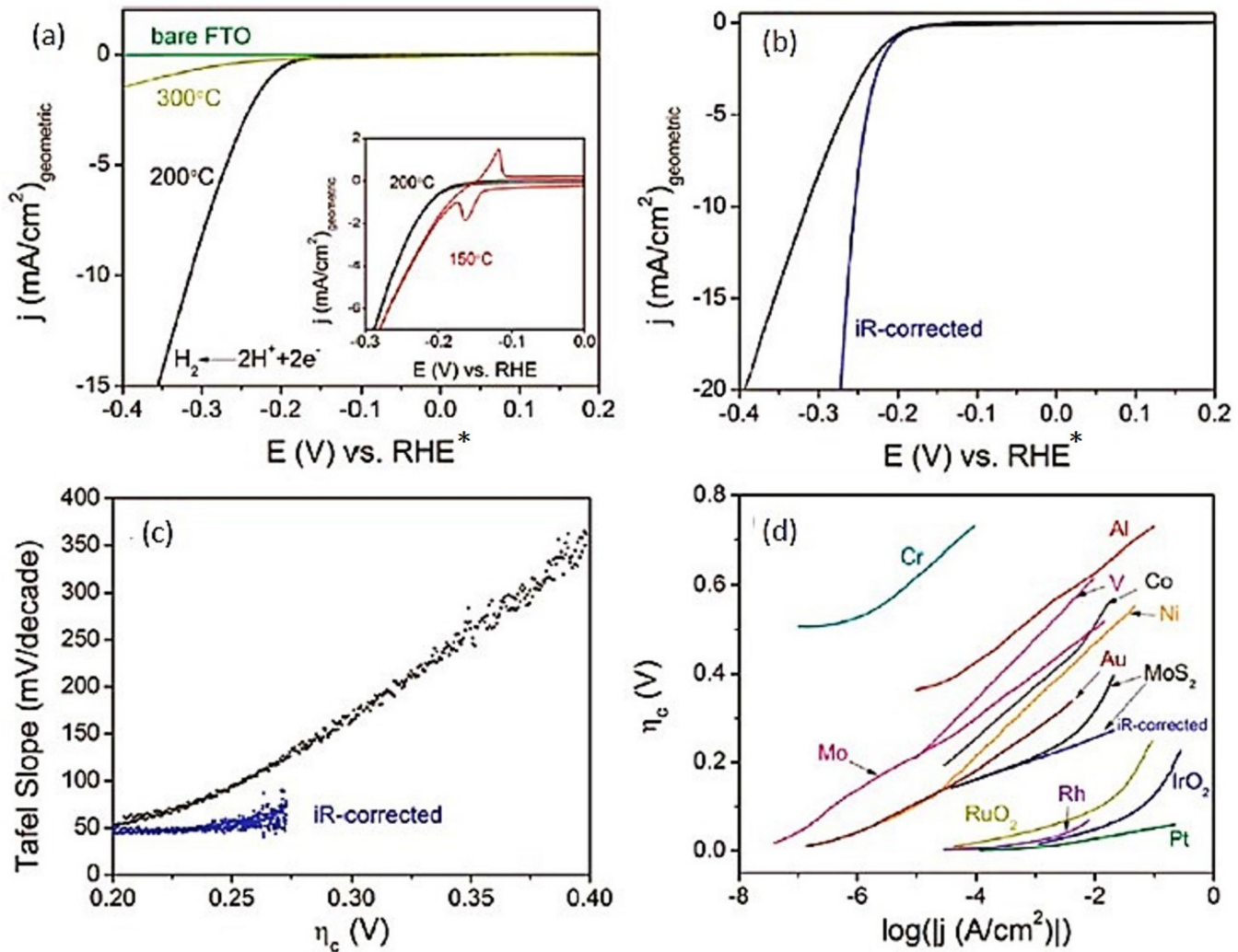

Figure 12. Electrochemical activity of $\mathrm{MoO}_{3}-\mathrm{MoS}_{2}$ nanowires [23]. (a) Cyclic voltammograms of nanowires sulfidized at $200{ }^{\circ} \mathrm{C}$ and $300^{\circ} \mathrm{C}$. The inset shows a comparison between nanowires sulfidized at 150 and at $200^{\circ} \mathrm{C}$. (b) The activity of the nanowires sulfidized at $200^{\circ} \mathrm{C}$ presented with its iR-corrected data. iR correction: to remove the background interference; RHE: reversible hydrogen electrode. (c) Tafel slope produced by taking a derivative of the Tafel plot in (d). (d) Comparison with digitized data of HER measurements at $25{ }^{\circ} \mathrm{C}$ for other materials. HER: hydrogen evolution reaction. FTO: Fluorine-doped tin oxide.

Furthermore, in 2017, Qu et al. [24] found that the vanadium (V)-doped nickel sulfide $\left(\mathrm{Ni}_{3} \mathrm{~S}_{2}\right)$ nanowire arrays exhibited an excellent electrocatalytic performance for HER [24]. As shown in the SEM and HRTEM images in Figures 13 and $14, \mathrm{~V}$-doped $\mathrm{Ni}_{3} \mathrm{~S}_{2}$ nanowire $\left(\mathrm{V}^{-} \mathrm{Ni}_{3} \mathrm{~S}_{2}-\mathrm{NW}\right)$ arrays grow uniformly on the nickel foam. This report also indicates that pure a $\mathrm{Ni}_{3} \mathrm{~S}_{2}$ nanowire cannot be 
manufactured at $160{ }^{\circ} \mathrm{C}$ or lower temperatures without oxidizing the $\mathrm{Ni}$ foam or introducing copolymer into the solution [24].
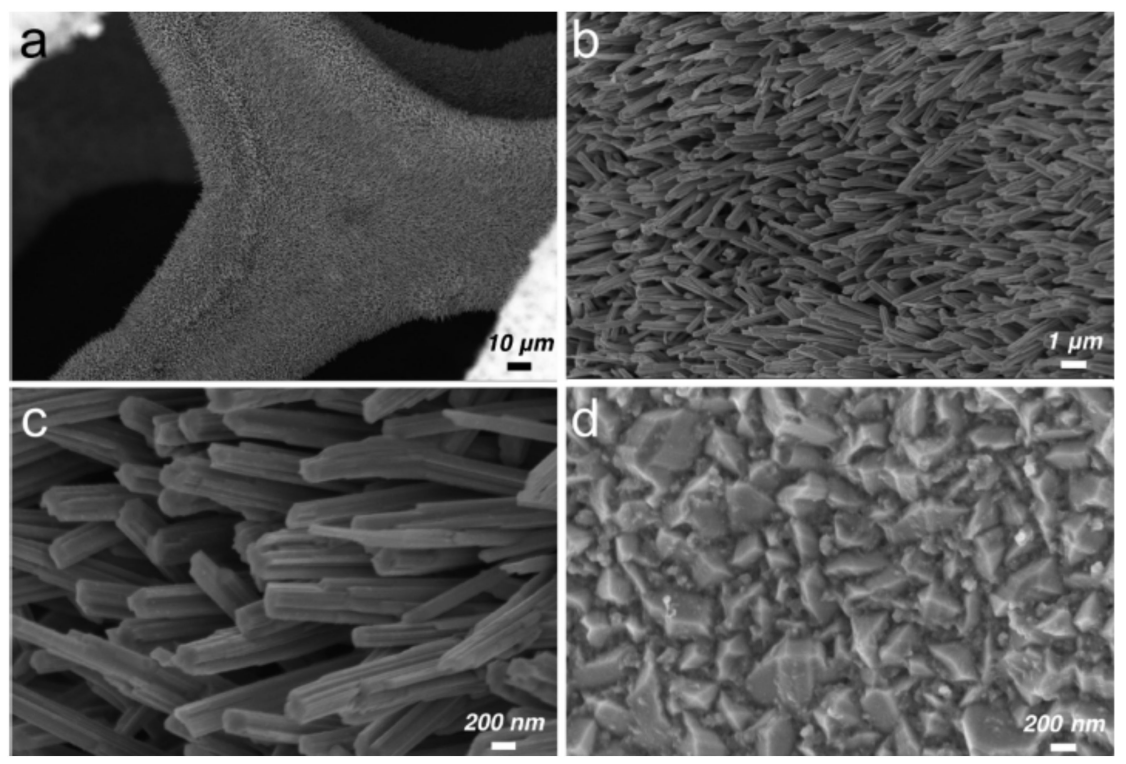

Figure 13. SEM images of (a-c) V-doped $\mathrm{Ni}_{3} \mathrm{~S}_{2}$ nanowire arrays and (d) pure $\mathrm{Ni}_{3} \mathrm{~S}_{2}$ nanoparticles on nickel foams [24]. SEM: Scanning electron microscope.
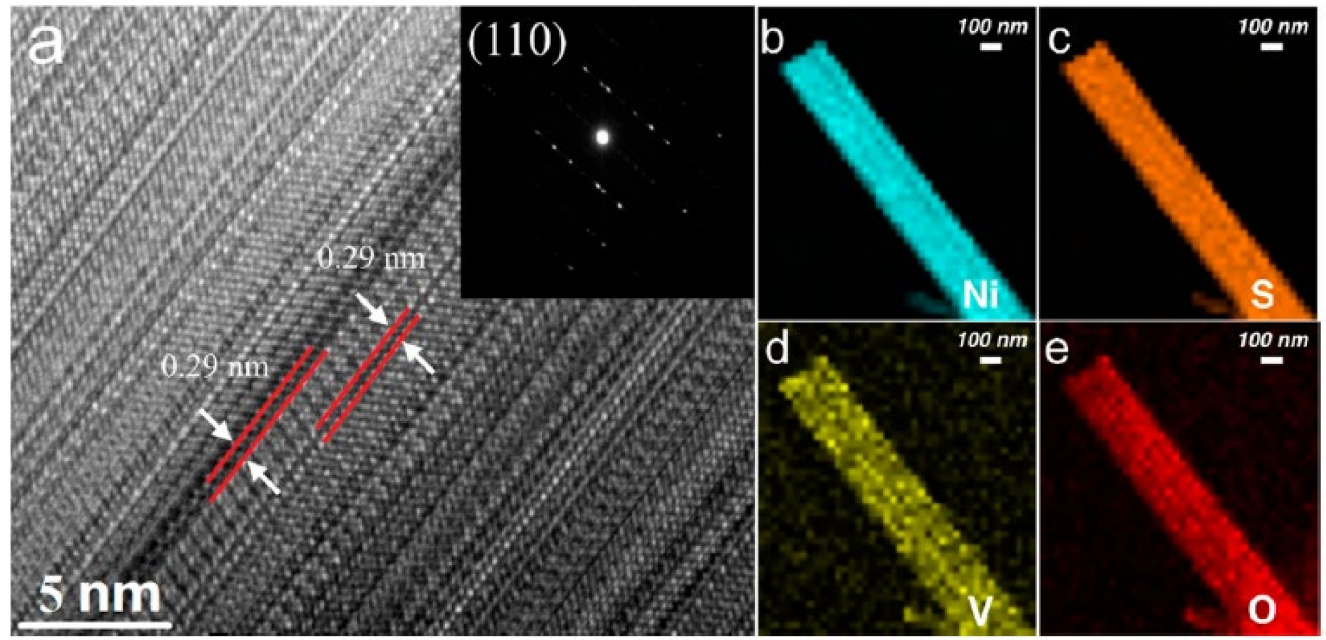

Figure 14. HRTEM image of single $\mathrm{V}$-doped $\mathrm{Ni}_{3} \mathrm{~S}_{2}$ nanowire arrays, (a) and EDS element maps of the single V-doped $\mathrm{Ni}_{3} \mathrm{~S}_{2}$ nanowire: (b) nickel, (c) sulfur, (d) vanadium, and (e) oxygen. The inset in panel a is the SAED pattern [24]. HRTEM: high resolution transmission electron microscope; EDS: energy-dispersive X-ray spectroscopy; SAED: selected area electron diffraction.

In the polarization curve (Figure 15a), $\mathrm{V}-\mathrm{Ni}_{3} \mathrm{~S}_{2}-\mathrm{NWs}$ demonstrate a lower overpotential $(\sim 203 \mathrm{mV})$ than the pure $\mathrm{Ni}$ and $\mathrm{Ni}_{3} \mathrm{~S}_{2}$ nanoparticles $(\sim 232 \mathrm{mV})$ at a current density of $20 \mathrm{~mA} \mathrm{~cm}^{-2}$. It was also found that, after thousands of cycles under the same condition, $\mathrm{V}-\mathrm{Ni}_{3} \mathrm{~S}_{2}-\mathrm{NWs}$ enhance the performance remarkably and remain stabilized. Moreover, at a current density of $10 \mathrm{~mA} \mathrm{~cm}{ }^{-2}$, its overpotential is reduced from 157 to $68 \mathrm{mV}$ after 7000 cycles (Figure 15b), which is better than $\mathrm{MoS}_{2} / \mathrm{Ni}_{3} \mathrm{~S}_{2}$ nanosheets $(110 \mathrm{mV})$ [25] and $\mathrm{MoO}_{\mathrm{x}} / \mathrm{Ni}_{3} \mathrm{~S}_{2}(106 \mathrm{mV})$ grown on nickel foams under the same condition [26]. Compared with the Tafel slope of the pure $\mathrm{Ni}$ foam and pure $\mathrm{Ni}_{3} \mathrm{~S}_{2}$ nanostructure (Figure $15 \mathrm{c}$ ), $\mathrm{V}-\mathrm{Ni}_{3} \mathrm{~S}_{2}-\mathrm{NW}$ shows the smallest Tafel slope value $(112 \mathrm{mV})$. Additionally, $\mathrm{V}$-doped $\mathrm{Ni}_{3} \mathrm{~S}_{2}$, in improving the free carrier density near the Fermi level, leads to an enhancement of the catalytic activity, which is also proven via first-principles calculations in this article [24]. 

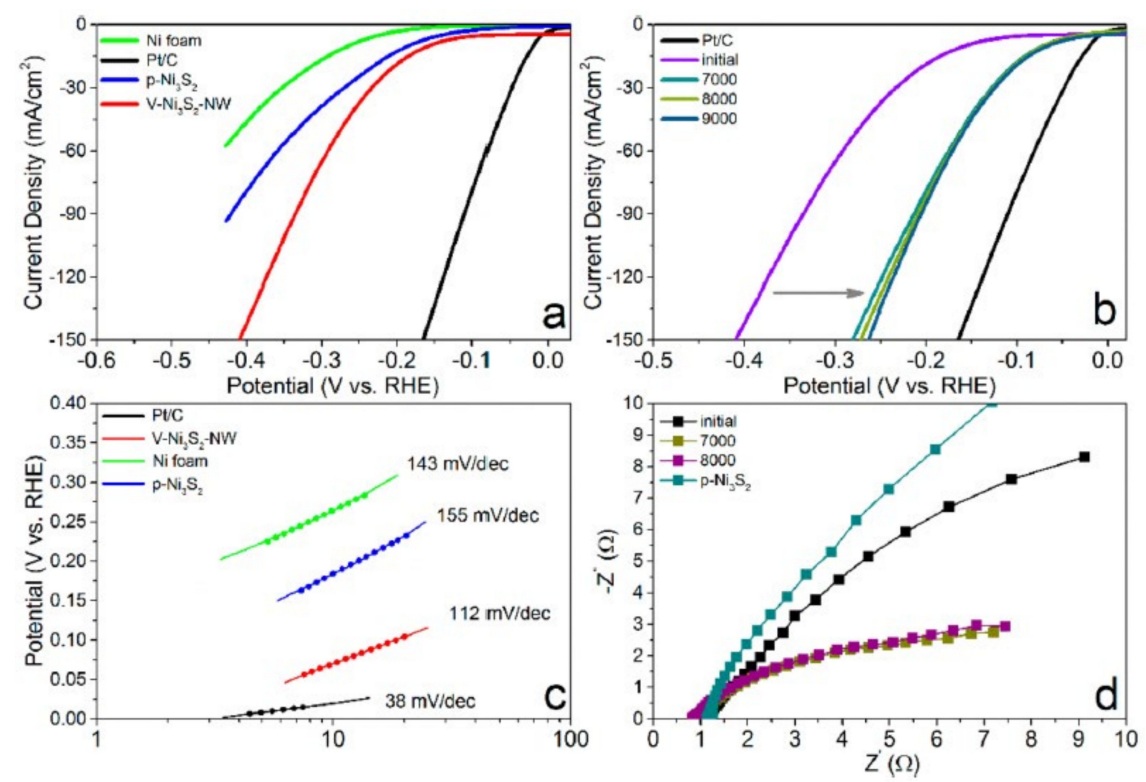

Figure 15. (a) Polarization curves of samples after an activation test, (b) polarization curves of V-doped $\mathrm{Ni}_{3} \mathrm{~S}_{2}$ nanowires after thousands of linear sweep voltammetry cycles and $\mathrm{Pt} / \mathrm{C}$, (c) Tafel plots of stabilized samples, and (d) Nyquist plots of stabilized V-doped $\mathrm{Ni}_{3} \mathrm{~S}_{2}$ nanowire arrays and pure $\mathrm{Ni}_{3} \mathrm{~S}_{2}$ nanoparticles [24].

\subsection{One-Dimensional Nanotube}

By optimizing the growth condition, $\mathrm{Xu}$ et al. [27] successfully synthesized ternary $\mathrm{WS}_{2(1-\mathrm{x})} \mathrm{Se}_{2 \mathrm{x}}$. nanotubes (NTs) and could systematically control the composition of $S$ and Se on the carbon fibers [27]. In this report, they could also identify and compare the electrocatalytic activity of $\mathrm{WS}_{2}, \mathrm{WSe}_{2}$, and $\mathrm{WS}_{2(1-\mathrm{x})} \mathrm{Se}_{2 x}$ nanotubes, respectively. From the TEM image (Figure 16), the as-prepared $\mathrm{WS}_{2}, \mathrm{WSe}_{2}$ and $W_{2(1-x)} S_{2 x}$ exhibit multiwall nanotubes. In general, NTs display a full opening, but some $\mathrm{WS}_{2}$ NTs seem to be sealed when the growth is terminated. Besides, many previous reports have implied that the exposed edge sites and conductivity of TMCs are essential to an impressive HER performance [28-30]. The HRTEM images show the layer dislocations and defects (pointed out by red arrows) in the wall, as shown in Figure 16b,d; meanwhile, NTs demonstrate a large surface area because of their hollow structure.
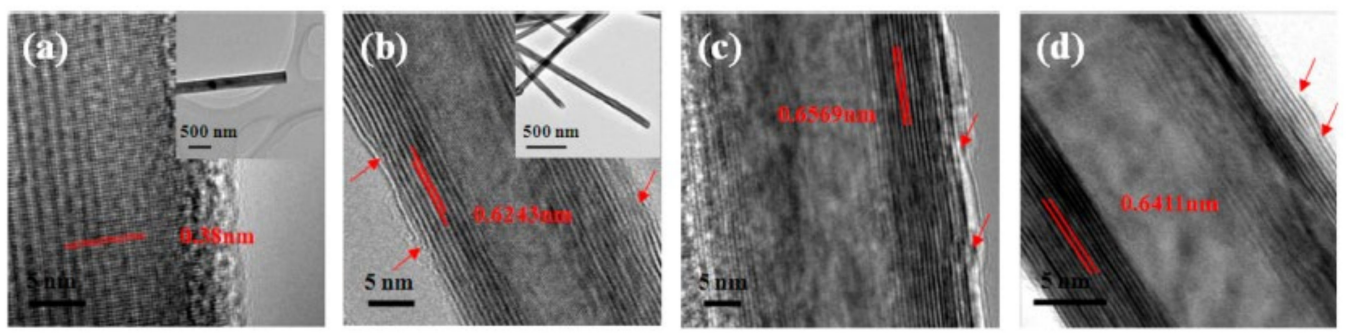

Figure 16. HRTEM images of (a) $\mathrm{WO}_{3} \mathrm{NWs}$, and (b) $\mathrm{WS}_{2}$, (c) $\mathrm{WSe}_{2}$ and (d) $\mathrm{WS}_{2(1-\mathrm{x})} \mathrm{Se}_{2 \mathrm{x}} \mathrm{NTs}$ [27]. HRTEM: High resolution transmission electron microscope; NWs: nanowires; NTs: nanotubes.

The electrocatalytic measurements show that the electrocatalytic properties of $\mathrm{WSe}_{2}$ and $\mathrm{WS}_{2}$ NTs are similar; the $\mathrm{WS}_{2(1-\mathrm{x})} \mathrm{Se}_{2 \mathrm{x}} \mathrm{NTs}(\mathrm{x}=0.52)$ demonstrate the best catalytic activity among all NT electrocatalysts (Figure 17a). According to the previous work, changing the geometry of the $\mathrm{TX}_{2}$-type inorganic nanotubes $(\mathrm{T}=\mathrm{Mo}, \mathrm{W} ; \mathrm{X}=\mathrm{S}$, Se, $\mathrm{Te}$ ) can elongate the $\mathrm{T}-\mathrm{X}$ bond lengths, which influences their electronic properties [31], and comprised of different elements can bring about the synergistic effect of rich active sites and a great conductivity in the electrocatalyst [32]. Thus, the ternary $\mathrm{WS}_{2(1-x)} \mathrm{Se}_{2 x} \mathrm{NTs}$ process a higher number of active sites and a higher conductivity for the HER performance. This can 
also be confirmed by other measurements. A lower Tafel slope of $\sim 105 \mathrm{mV} /$ decade (Figure $17 \mathrm{~b}$ ), $R_{\mathrm{ct}}$ of $\sim 204 \Omega \mathrm{cm}^{2}$ (Figure 17d), higher exchange current density $\left(0.029 \mathrm{~mA} \mathrm{~cm}^{-2}\right)$, and large electrochemical double-layer cy (EDLC) $\left(1.186 \mathrm{mF} \mathrm{cm}^{-2}\right)$ (Figure 17c) demonstrate that $\mathrm{WS}_{2(1-\mathrm{x})} \mathrm{Se}_{2 \mathrm{x}} \mathrm{NT}$ is an excellent catalyst for HER.
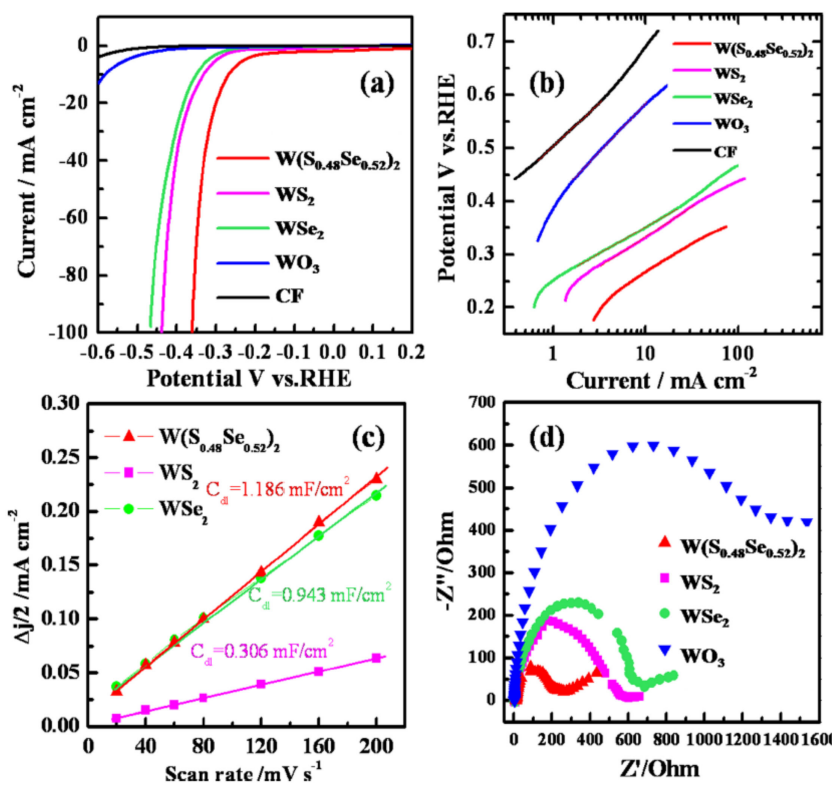

Figure 17. HER electrocatalytic properties of $\mathrm{WO}_{3} \mathrm{NWs}, \mathrm{WS}_{2}, \mathrm{WSe}_{2}$, and $\mathrm{WS}_{2(1-\mathrm{x})} \mathrm{Se}_{2 \mathrm{x}} \mathrm{NTs}$. (a) Polarization curves (after iR correction). (b) Corresponding Tafel plots. (c) Linear fitting of the capacitive currents of the catalysts versus the scan rate. (d) Nyquist plots of different samples [27]. HER: hydrogen evolution reaction; NTs: nanotubes; iR correction: to remove the background interference.

\subsection{One-Dimensional Nanoneedle}

Lee et al. [33] synthesized the beaded stream-like $\mathrm{CoSe}_{2}$ nanoneedle array (CoSe 2 -BSND) directly formed on the flexible titanium foil by a two-step hydrothermal-selenization approach (Figure 18), which is the unique hierarchical structure shown in Figure 18 [33]. Through this architecture, CoSe 2 -BSND possesses highly accessible surface active sites, a strongly attractive force between water and the surface of nanoneedles, and it enhances charge transfer kinetics. The SEM images (Figure 19) show that the nanoneedle arrays maintain the morphologies before and after the selenization process.

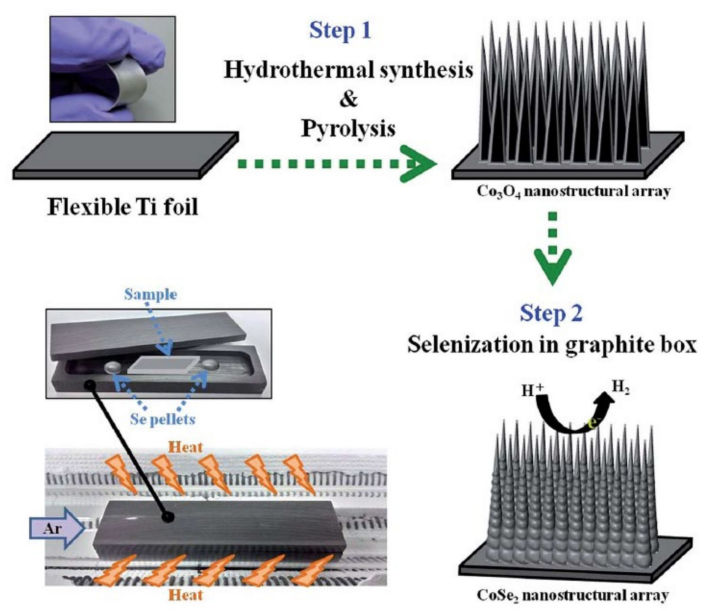

Figure 18. Schematic depiction of the synthesis of $\mathrm{CoSe}_{2}$ nanoneedle arrays [33]. 

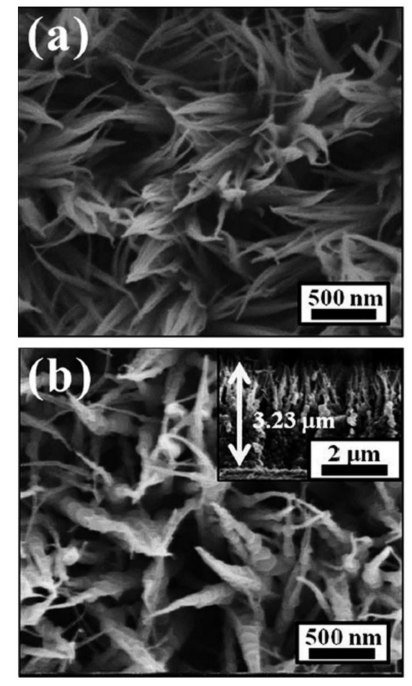

Figure 19. SEM images of (a) $\mathrm{Co}_{3} \mathrm{O}_{4}$ and (b) $\mathrm{CoSe}_{2}$ nanoneedle arrays [33]. SEM: Scanning electron microscope.

In Figure 20, compared with the Ti foil and Se-treated Ti foil, $\mathrm{CoSe}_{2}$-BSND demonstrates a better activity of HER at a current density of $20 \mathrm{~mA} \mathrm{~cm}^{-2}$. Moreover, according to the published reports related to TMC-based HER catalysts [34,35], i.e., electrocatalysis of the hydrogen evolution reaction by electrodeposited amorphous cobalt selenide films, the activity of $\mathrm{CoSe}_{2}$-BSND belongs to the top group of these catalysts under similar conditions (Table 4). For the Co-BSND, the Tafel slope is $77.5 \mathrm{mV} /$ decade; by contrast, $\mathrm{CoSe}_{2}$-BSND possesses a lower Tafel slope ( $48.5 \mathrm{mV} /$ decade), which means a faster discharge of protons (Figure 21). Therefore, the presence of selenium in the Co lattice prefers proton adsorption kinetics. In Figure 22, we can see that the surface contact angle of $\mathrm{CoSe}_{2}$-BSND is close to zero, which indicates an increase in the effective electrode surface area and a decrease in the mass transport resistance. Likewise, a high exchange current density and low charge-transfer resistance confirm that $\mathrm{CoSe}_{2}$-BSND is an outstanding HER catalyst.
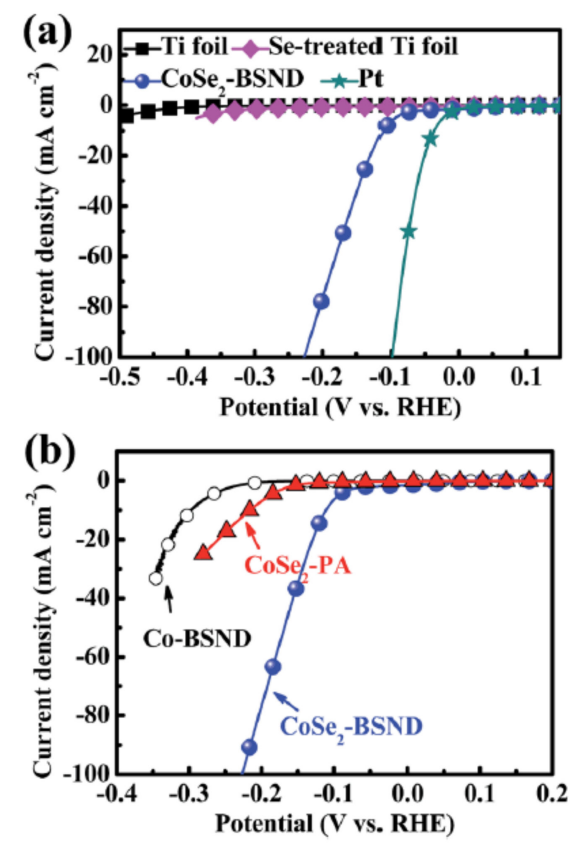

Figure 20. (a) The polarization curves of different CEs. (b) The polarization curves of Co-BSND, $\mathrm{CoSe}_{2}-\mathrm{PA}$, and $\mathrm{CoSe}_{2}$-BSND [33]. CEs: counter electrodes; Co-BSND: beaded stream-like Co nanoneedle array; $\mathrm{CoSe}_{2}$-PA: $\mathrm{CoSe}_{2}$ particle; $\mathrm{CoSe}_{2}$-BSND: beaded stream-like $\mathrm{CoSe}_{2}$ nanoneedle array. 
Table 4. HER performance of one-dimensional TMDCs.

\begin{tabular}{|c|c|c|c|c|c|c|}
\hline Catalyst & Morphology & $\begin{array}{l}\text { Overpotential } \\
(\mathrm{mV})\end{array}$ & 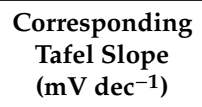 & $\begin{array}{l}\text { Current } \\
\text { Density } \\
\left(\mathrm{mA} \mathrm{cm}^{-2}\right)\end{array}$ & Electrolyte & Ref. \\
\hline $\begin{array}{c}\text { Core-shell } \\
\mathrm{MoO}_{3}-\mathrm{MoS}_{2}\end{array}$ & nanowire & $150-200$ & $50-60$ & N/A & $0.5 \mathrm{M} \mathrm{H}_{2} \mathrm{SO}_{4}$ & [23] \\
\hline V-doped $\mathrm{Ni}_{3} \mathrm{~S}_{2}$ & nanowire & 157 & 112 & N/A & $1 \mathrm{M} \mathrm{KOH}$ & [24] \\
\hline $\mathrm{WS}_{2(1-x)} \mathrm{Se}_{2 x} / \mathrm{CFs}$ & nanotube & 150-200 & 105 & 0.029 & $1 \mathrm{M} \mathrm{H}_{2} \mathrm{SO}_{4}$ & [27] \\
\hline $\mathrm{WSe}_{2} / \mathrm{CFs}$ & nanotube & $250-300$ & 99 & 0.003 & $1 \mathrm{M} \mathrm{H}_{2} \mathrm{SO}_{4}$ & [27] \\
\hline $\mathrm{WS}_{2} / \mathrm{CFs}$ & nanotube & $250-300$ & 113 & 0.0012 & $1 \mathrm{M} \mathrm{H}_{2} \mathrm{SO}_{4}$ & [27] \\
\hline $\mathrm{CoSe}_{2}$-BSND & nanoneedle & 125 & 48 & 0.043 & $0.5 \mathrm{M} \mathrm{H}_{2} \mathrm{SO}_{4}$ & [33] \\
\hline
\end{tabular}

HER: hydrogen evolution reaction; TMDCs: transition metal dichalcogenides; CF: carbon fiber; $\mathrm{CoSe}_{2}$-BSND: beaded stream-like $\mathrm{CoSe}_{2}$ nanoneedle array.
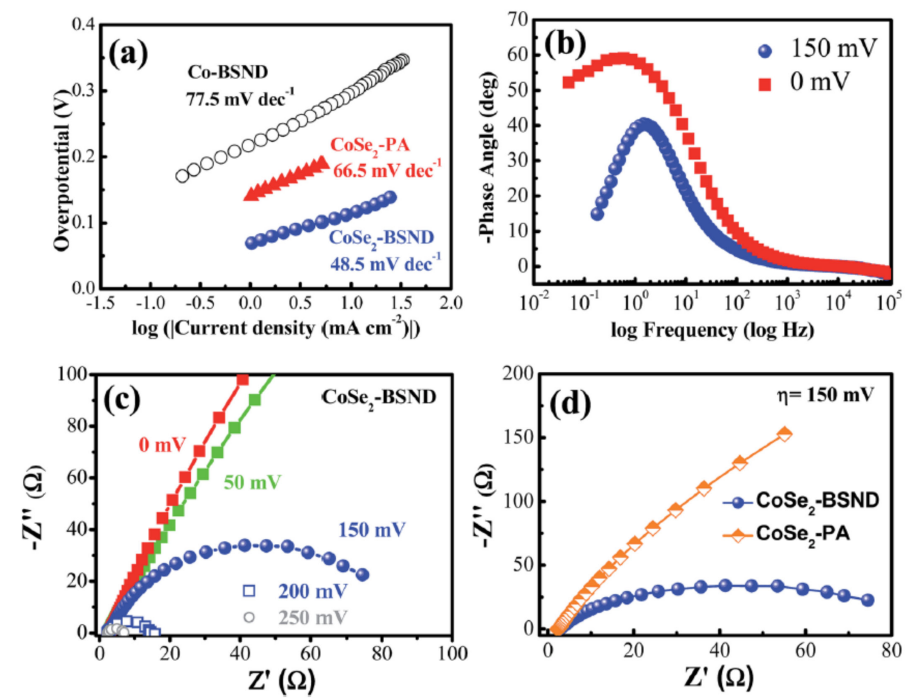

Figure 21. (a) Tafel plots of the electrodes (b) The Bode plots of the CoSe $e_{2}$-BSND electrode at overpotentials of 0 and $150 \mathrm{mV}$. (c) The Nyquist plots of beaded stream-like CoSe $\mathrm{C}_{2}$-BSND at overpotentials changing from 0 to $250 \mathrm{mV}$ in a $0.5 \mathrm{M} \mathrm{H}_{2} \mathrm{SO}_{4}$ solution. (d) Comparison of the Nyquist plots [33]. CoSe $e_{2}$-BSND: beaded stream-like $\mathrm{CoSe}_{2}$ nanoneedle array.
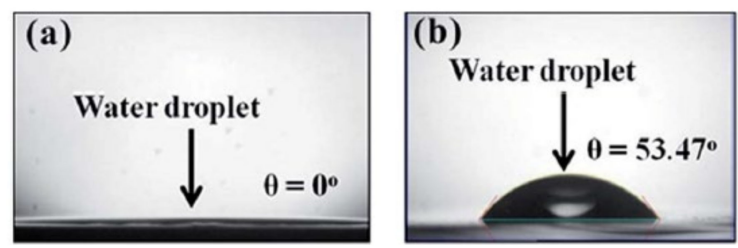

Figure 22. Surface contact angles of water droplets on electrodes with (a) the $\mathrm{CoSe}_{2}-\mathrm{BSND}$ and (b) the $\mathrm{CoSe}_{2}$-PA electrodes [33]. $\mathrm{CoSe}_{2}$-BSND: beaded stream-like $\mathrm{CoSe}_{2}$ nanoneedle array; $\mathrm{CoSe}_{2}$-PA: $\mathrm{CoSe}_{2}$ particle.

\section{Two-/Three-Dimensional Materials for the Counter Electrode of Dye-Sensitized Solar Cells}

\subsection{Molybdenum Disulfide $\left(\mathrm{MoS}_{2}\right)$}

Recently, 2D TMDCs have attracted huge attention due to their excellent physical and chemical properties. Among them, molybdenum disulfide $\left(\mathrm{MoS}_{2}\right)$, a layered material with a thickness of only three atoms, is one of the most typical TMDC materials. Bulky MoS 2 is a semiconductor with an indirect energy gap of $1.29 \mathrm{eV}$, while monolayer $\mathrm{MoS}_{2}$ (which can be stripped from bulk MoS 2 or prepared by chemical vapor deposition) is a semiconductor material with a direct energy gap of $1.9 \mathrm{eV}$ [36]. 


\section{2. $\mathrm{MoS}_{2} /$ Graphene Composite}

Yue et al. [37] used a $\mathrm{MoS}_{2} /$ graphene flake composite as a Pt-free CE to catalyze the iodine/iodide $\left(\mathrm{I}^{-} / \mathrm{I}_{3}{ }^{-}\right)$redox couple in DSSCs [37]. The SEM images of the $\mathrm{MoS}_{2}$, graphene, and $\mathrm{MoS}_{2} /$ graphene composite are shown in Figure 23. In the CV results, the cathodic current density of the $\mathrm{MoS}_{2}$ /graphene composite $\mathrm{CE}$ for the $\mathrm{I}_{3}{ }^{-}$reduction was higher than that of $\mathrm{MoS}_{2}$, graphene, and $\mathrm{Pt} \mathrm{CEs}$. The $\mathrm{J}-\mathrm{V}$ curves of DSSCs with $\mathrm{MoS}_{2}$ /graphene as CEs at different thicknesses were investigated and compared with that of the DSSCs using conventional Pt CEs (Figure 24). The performances of the DSSCs were affected by the $\mathrm{MoS}_{2}$ /graphene layer number (Figure 24a,d). The $\mathrm{J}_{\mathrm{sc}}$ and open-circuit voltage $\left(V_{\mathrm{oc}}\right)$ increased when the layer number increased from monolayer to trilayer. From $0.5 \mathrm{wt} \%$ (weight percent) to $1.5 \mathrm{wt} \%$, the graphene content also reflected a decrease in $R_{\mathrm{ct}}$ for $\mathrm{MoS}_{2} /$ graphene CEs (Figure 24d). The PCE of the DSSCs with $\mathrm{MoS}_{2} /$ graphene composite CEs with $1.5 \mathrm{wt} \%$ graphene showed an impressive efficiency of 5.98\%, which was very close to the PCE of DSSCs with Pt CEs (6.23\%) (Figure 24b). The results proved that the $\mathrm{MoS}_{2} /$ graphene composite is a low-cost alternative to the Pt CE.
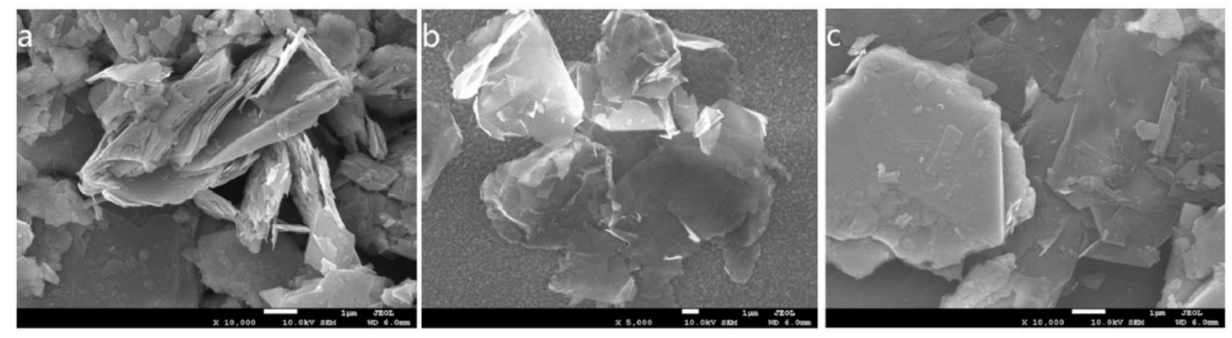

Figure 23. SEM images of (a) $\mathrm{MoS}_{2}$, (b) graphene, and (c) $\mathrm{MoS}_{2} /$ graphene powders [37]. SEM: Scanning electron microscope.

(a)

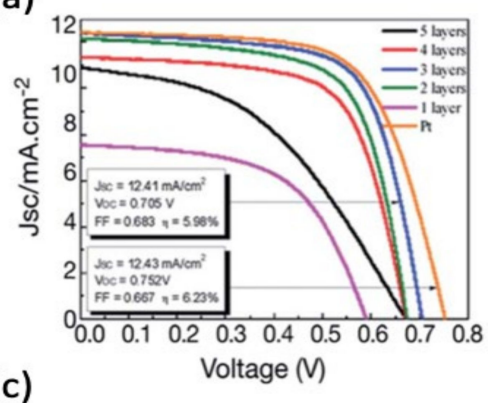

(b)

(c)
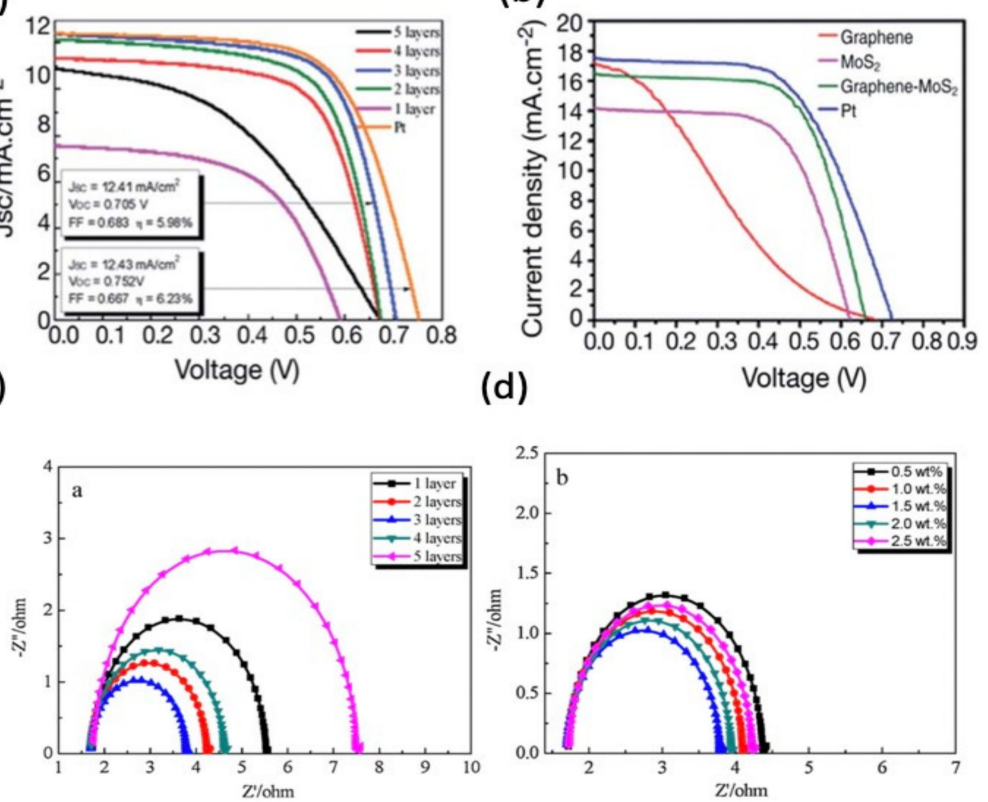

Figure 24. (a) J-V curves of DSSCs with Pt CE and $\mathrm{MoS}_{2}$ /graphene CE at different thickness. (b) J-V curves of DSSCs with Pt and other CE. (c) Nyquist plots of the cells fabricated from $\mathrm{MoS}_{2} /$ graphene CE prepared at various thicknesses. (d) EIS of the cells of $\mathrm{MoS}_{2} /$ graphene $\mathrm{CE}$ with different graphene contents [37]. J-V: photocurrent density-photovoltage; DSSCs: dye-sensitized solar cell; CE: counter electrode; EIS: electrochemical impedance spectroscopy. 


\section{3. $\mathrm{MoS}_{2} / \mathrm{N}$-Doped Graphene Composite}

Fan et al. [38] successfully synthesized nitrogen-doped graphene (NGr) with a MoS 2 (NM-8) composite film prepared by the drop-coating method as a CE for DSSCs (Figure 25) [38]. The electrocatalytic activity of NM-8 composite films for the reduction of triiodide $\left(\mathrm{I}_{3}{ }^{-}\right)$was much higher than that of the pristine $\mathrm{N}$-graphene and $\mathrm{MoS}_{2}$ thin films because of the lower $R_{\mathrm{ct}}$ at the $\mathrm{CE} /$ electrolyte interface (Table 5). With the introduction of NGr, there is an increase in the electrical conductivity of the composite film. Here, the $\mathrm{N}$ atom attracts the electron clouds from nearby $\mathrm{C}$ atoms because of the difference in the electronegativity between $\mathrm{C}$ and $\mathrm{N}$, promoting the electron transfer and hence forming an active site [39]. Furthermore, the electrocatalytic activity of the composite film increases due to the addition of $\mathrm{MoS}_{2}$, which provides more active sites on its edges. The performance of DSSCs with NM-8 composite films as CEs displays a promising efficiency of $7.82 \%$, which is just slightly lower than that of DSSCs with the Pt CE (8.25\%).

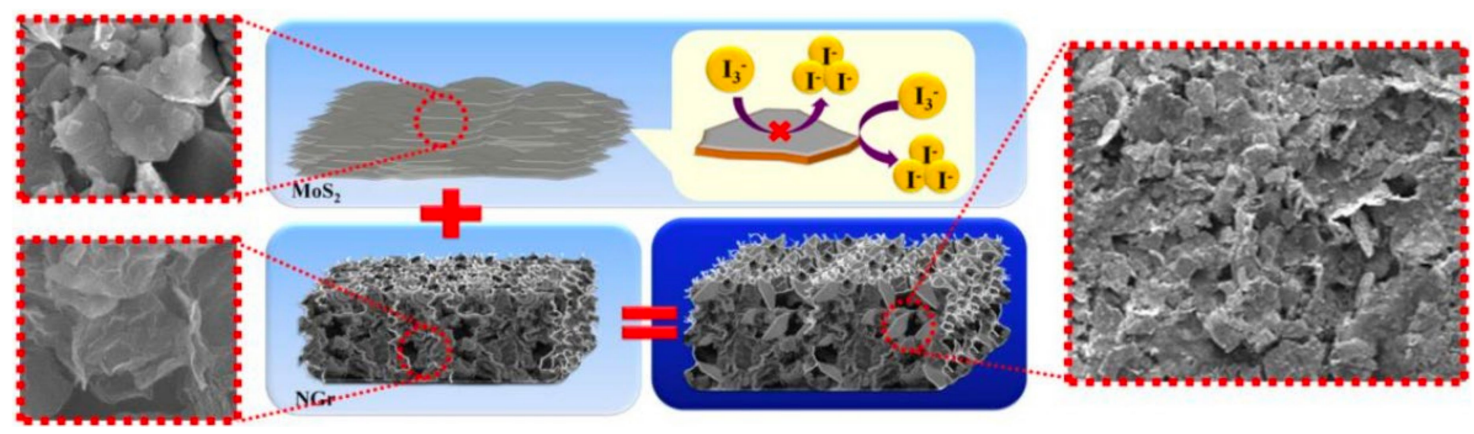

Figure 25. A schematic illustration of the electrocatalytic reduction of triiodide with the NM- 8 composite films [38]. NM-8: nitrogen-doped graphene with $\mathrm{MoS}_{2}$.

Table 5. Analysis of DSSCs based on the films of Pt, NGr, MoS 2 , and NM-8 CE [38].

\begin{tabular}{|c|c|c|c|c|c|c|c|c|c|c|}
\hline CE & $\begin{array}{c}J_{p c} \\
\left(\mathrm{mAcm}^{-2}\right)\end{array}$ & $\begin{array}{l}\Delta E_{\mathrm{p}} \\
\text { (V) }\end{array}$ & $\begin{array}{c}J_{\mathrm{sc}-\mathrm{IPCE}} \\
\left(\mathrm{mA} \mathrm{cm}^{-2}\right)\end{array}$ & $\begin{array}{c}k_{0} \\
\left(\mathrm{~cm} \mathrm{~s}^{-1}\right)\end{array}$ & $\begin{array}{c}A_{\mathrm{e}} \\
\left(\mathrm{cm}^{2}\right)\end{array}$ & $\begin{array}{c}R_{\mathrm{s}} \\
\left(\Omega \mathrm{cm}^{2}\right)\end{array}$ & $\begin{array}{c}R_{\mathrm{ct}} \\
\left(\Omega \mathrm{cm}^{2}\right)\end{array}$ & $\begin{array}{c}Z_{W} \\
\left(\Omega \mathrm{cm}^{2}\right)\end{array}$ & $\begin{array}{l}R_{\mathrm{ct}-T a f e l} \\
\left(\Omega \mathrm{cm}^{2}\right)\end{array}$ & $\begin{array}{c}J_{0} \\
\left(\mathrm{~mA} \mathrm{~cm}^{-2}\right)\end{array}$ \\
\hline $\mathrm{Pt}$ & 2.55 & 0.38 & 12.82 & $3.75 \times 10^{-3}$ & 0.196 & 15.23 & 10.15 & 8.49 & 9.88 & 1.30 \\
\hline NGr & 0.49 & 0.72 & 10.16 & $1.34 \times 10^{-3}$ & 0.390 & 16.31 & 30.17 & 35.46 & 33.93 & 0.38 \\
\hline $\mathrm{MoS}_{2}$ & 0.52 & 0.91 & 10.89 & $7.04 \times 10^{-4}$ & 0.136 & 21.14 & 24.93 & 27.20 & 24.61 & 0.52 \\
\hline NM-8 & 2.06 & 0.58 & 12.03 & $2.40 \times 10^{-3}$ & 0.730 & 15.60 & 16.73 & 18.12 & 16.15 & 0.80 \\
\hline
\end{tabular}

DSSCs: dye-sensitized solar cells; NGr: nitrogen-doped graphene; NM-8: nitrogen-doped graphene with $\mathrm{MoS}_{2}$; CE: counter electrode; $J_{p c}$ : peak current density; $\Delta E_{p}$ : peak separation; $\mathrm{V}_{\mathrm{oc}}$ : open-circuit voltage; $J_{\mathrm{sc}}$ : photocurrent density; IPCE: incident photo-to-current conversion efficiency; $k_{0}$ : rate constant; $A_{\mathrm{e}}$ : surface area; $R_{\mathrm{s}}$ : solution resistance; $R_{\mathrm{ct}}$ : charge-transfer resistance; $Z_{\mathrm{w}}$ : warburg imperdance; $J_{0}$ : exchange current density.

\subsection{Nickel Disulfide $\left(\mathrm{NiS}_{2}\right)$}

Nickel disulfide $\left(\mathrm{NiS}_{2}\right)$ can be synthesized by different methods, such as vapor phase reaction, hydrothermally, ultrasonic irradiation and solvothermal [40]. Nickel disulfide $\left(\mathrm{NiS}_{2}\right)$ is a semiconductor with a pyrite structure, which exhibits great electrical, optical, and catalytic properties in many different morphologies [41,42]. Li et al. [43]. synthesized the composite of $\mathrm{NiS}_{2}$ nanoparticles and reduced graphene oxide $\left(\mathrm{NiS}_{2} @ \mathrm{RGO}\right)$ via a hydrothermal reaction (Figure 26a) [43]. GO serves as a substrate for the nucleation of $\mathrm{NiS}_{2}$ nanoparticles, which results in well-dispersed $\mathrm{NiS}_{2}$ nanoparticles on a graphene oxide sheet (Figure 26b). The stretching vibration peak of $\mathrm{NiS}_{2}$ at $480 \mathrm{~cm}^{-1}$ can be observed in the samples of $\mathrm{NiS}_{2}$ and $\mathrm{NiS}_{2} @ \mathrm{RGO}$ (Figure 26c). Judging by the higher reduction current and smaller redox peak potential separation, the catalytic activity of $\mathrm{NiS}_{2} @ \mathrm{RGO}$ shows a superior performance when compared to that of $\mathrm{NiS}_{2}$ - and RGO-only electrodes (Figure 26d). The DSSCs with the $\mathrm{NiS}_{2} @ \mathrm{RGO}$ CE have the highest PCE at $8.55 \%$, which is ascribed to a low $R_{\mathrm{ct}}$ (Table 6). On the other hand, recently, the group-10 noble TMDCs have been reintroduced as new 2D materials, such as MX2, where M is a noble metal (Pd or Pt) and $\mathrm{X}$ is a chalcogenide element ( $\mathrm{S}, \mathrm{Se}$, and $\mathrm{Te}$ ). They display many attractive properties, including a widely tunable bandgap and excellent catalytic ability $[44,45]$. 
(a)

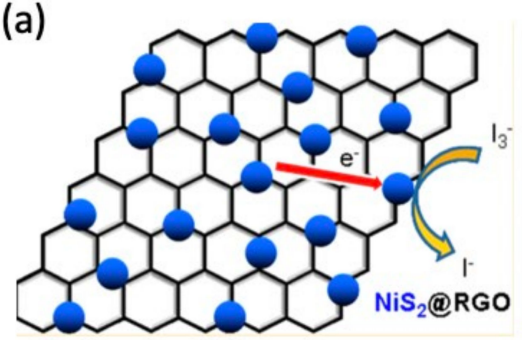

(c)

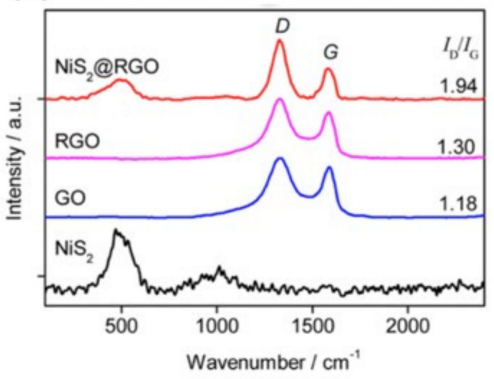

(b)

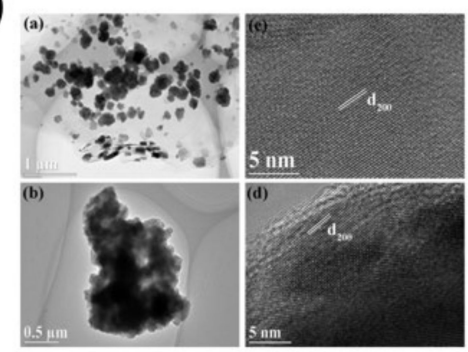

(d)

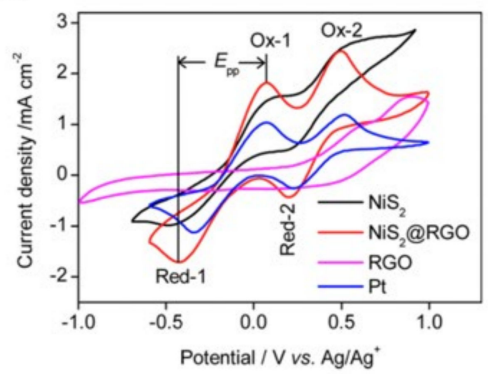

Figure 26. (a) Illustration of how the electrolyte reacts with the material. (b) HRTEM images of as-synthesized $\mathrm{NiS}_{2} @ \mathrm{RGO}(\mathbf{a}, \mathbf{c})$ and $\mathrm{NiS}_{2}(\mathbf{b}, \mathbf{d})$. (c) Raman spectra of $\mathrm{NiS}_{2}$ nanoparticles and $\mathrm{NiS}_{2} @ \mathrm{RGO}, \mathrm{RGO}, \mathrm{GO}$, and $\mathrm{NiS}_{2}$. (d) $\mathrm{CV}$ of iodide/triiodide redox species for $\mathrm{NiS}_{2}$ nanoparticles and $\mathrm{NiS}_{2} @ \mathrm{RGO}, \mathrm{NiS}_{2}, \mathrm{Pt}$, and RGO counter electrodes [43]. HRTEM: high resolution transmission electron microscope; $\mathrm{NiS}_{2} @ \mathrm{RGO}: \mathrm{NiS}_{2}$ nanoparticles and reduced graphene oxide; $\mathrm{RGO}$ : reduced graphene oxide; GO: graphene oxide; $\mathrm{CV}$ : cyclic voltammetry.

Table 6. A schematic illustration of the photovoltaic and electrochemical parameters for different CEs [43].

\begin{tabular}{cccccccc}
\hline CEs & $\begin{array}{c}\boldsymbol{V}_{\mathbf{~ o c}} \\
(\mathbf{m V})\end{array}$ & $\begin{array}{c}\boldsymbol{J}_{\mathbf{s c}} \\
\left(\mathbf{m A ~} \mathbf{~ c m}^{-2}\right)\end{array}$ & $\mathbf{F F}$ & $\mathbf{P C E} \mathbf{( \% )}$ & $\begin{array}{c}\boldsymbol{R}_{\mathbf{s}} \\
\left(\boldsymbol{\Omega} \mathbf{~ c m}^{2}\right)\end{array}$ & $\begin{array}{c}\boldsymbol{R}_{\mathbf{c t}} \\
\left(\boldsymbol{\Omega} \mathbf{~ c m}^{2}\right)\end{array}$ & $\begin{array}{c}\boldsymbol{E}_{\mathbf{p p}} \\
(\mathbf{V})\end{array}$ \\
\hline $\mathrm{NiS}_{2}$ & 738 & 14.42 & 0.66 & 7.02 & 5.10 & 8.80 & 0.65 \\
$\mathrm{NiS}_{2} @ \mathrm{RGO}$ & 749 & 16.55 & 0.69 & 8.55 & 6.40 & 2.90 & 0.50 \\
$\mathrm{RGO}$ & 716 & 10.98 & 0.40 & 3.14 & 14.20 & 100.20 & $\mathrm{~N} / \mathrm{A}$ \\
$\mathrm{Pt}$ & 739 & 15.75 & 0.70 & 8.15 & 2.20 & 0.50 & 0.44 \\
\hline
\end{tabular}

CEs: counter electrodes; $V_{\mathrm{oc}}$ : open-circuit voltage; $J_{\mathrm{sc}}$ : photocurrent densit; FF: fill factor; PCE: power conversion efficiency; $R_{\mathrm{s}}$ : solution resistance; $R_{\mathrm{ct}}$ : charge-transfer resistance; $E_{\mathrm{pp}}$ : peak-to-peak separation.

\subsection{Tungsten Diselenide ( $\mathrm{WSe}_{2}$ )}

Hussain et al. [46] prepared $\mathrm{WSe}_{2} / \mathrm{W}$ by sputtering the $\mathrm{W}$ metal and then conducting a selenization annealing (Figures 27 and 28) [46]. In Figure 29b, $\mathrm{WSe}_{2} / \mathrm{W}$ has a smaller cathodic peak potential and a larger current density, which indicates its lower overpotential, better electrocatalytic capability, and faster reaction speed for $\mathrm{I}_{3}{ }^{-}$reduction (Figure 29b). The abovementioned can be ascribed to the low overall cell resistance. The slopes of the anodic or cathodic part of $\mathrm{WSe}_{2} / \mathrm{W}$ are higher than those of $\mathrm{Pt}$, which indicates a higher exchange current density on the electrode (Figure 29c). The EIS results show that the sheet resistance $\left(2.64 \Omega \mathrm{cm}^{2}\right)$ and $R_{\mathrm{ct}}\left(1.38 \Omega \mathrm{cm}^{2}\right)$ of the WSe $/ \mathrm{W}$ CE are smaller than those of Pt/FTO $\left(12.72 \Omega \mathrm{cm}^{2}\right.$ for the sheet resistance and $8.66 \Omega \mathrm{cm}^{2}$ for the $R_{\mathrm{ct}}$ ) (Figure 29d). The PCE of DSSCs with $\mathrm{WSe}_{2} / \mathrm{W}$ as CEs (8.22\%) showed a better performance than that of DSSCs that were based on Pt CEs (8.20\%). 


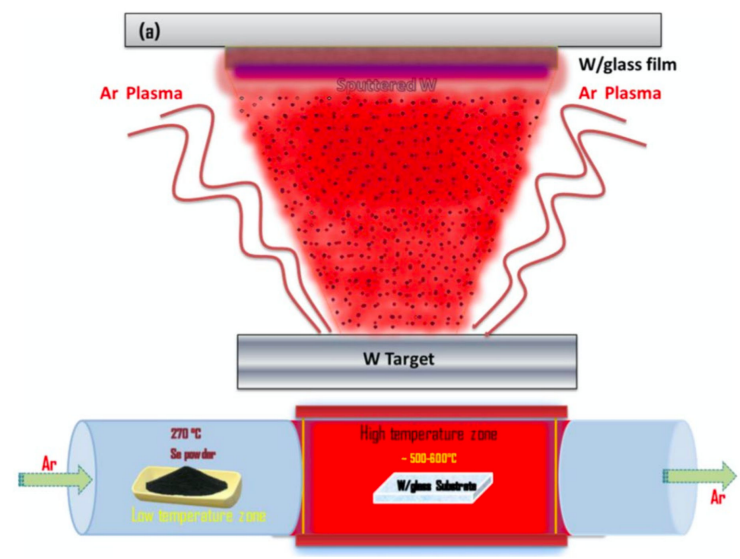

Figure 27. Schematic illustration of the setup for the selenization of $\mathrm{W}$ on $\mathrm{W}$-film coated $(\mathrm{WSe} / \mathrm{W})$ counter electrode [46].

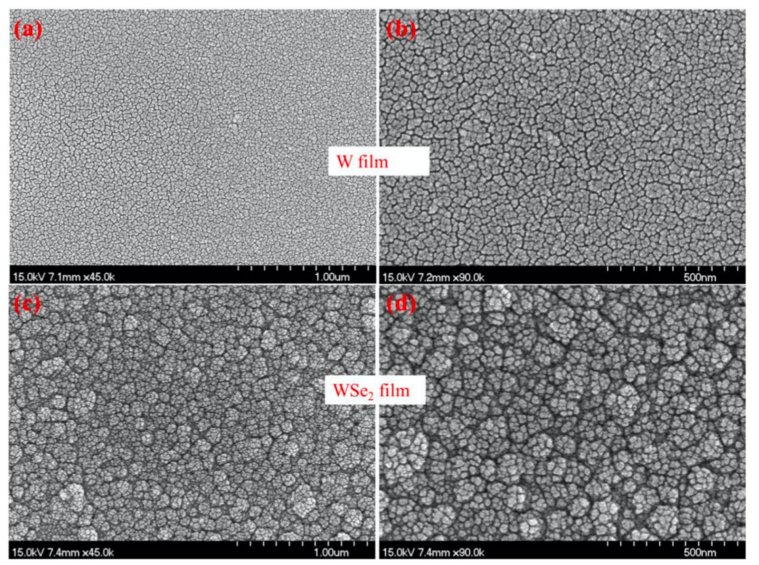

Figure 28. Surface morphology changes $(\mathbf{a}, \mathbf{b})$ before and $(\mathbf{c}, \mathbf{d})$ after selenization on the W surface [46].

(a)

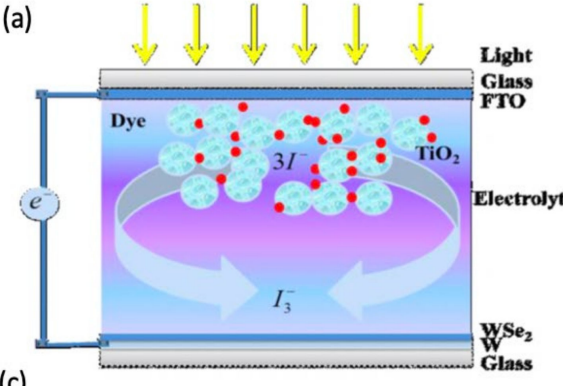

(c)

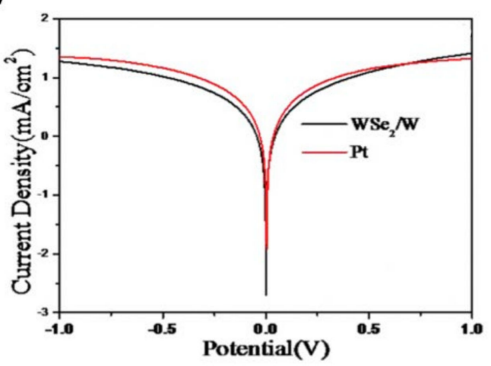

(b)

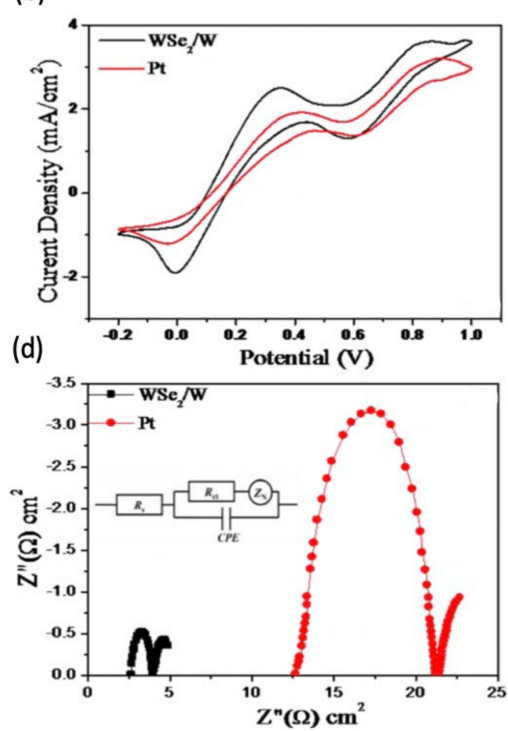

Figure 29. (a) The illustration of the selenization of $\mathrm{W}$ on $\mathrm{W}$-film coated $\left(\mathrm{WSe}_{2} / \mathrm{W}\right)$ structure as a CE in DSSCs. (b) Three-electrode cyclic voltammetry (CV) using $\mathrm{WSe}_{2} / \mathrm{W}$ and $\mathrm{Pt}$ as a WE in the electrolyte. (c) Tafel plot of symmetrical cells made of $\mathrm{WSe}_{2} / \mathrm{W}$ and Pt; (d) EIS of the spectra of $\mathrm{WSe}_{2} / \mathrm{W}$ and Pt [46]. CE: counter electrode; DSSCs: dye-sensitized solar cell; WE: working electrode; EIS: electrochemical impedance spectroscopy. 


\subsection{Nitrogen-Doped Graphene Hollow Nanoballs (N-GHBs)}

With its excellent electrical conductivity, high carrier mobility, mechanical strength, and chemical stability, graphene has become one of the potential noble-metal-free CEs in DSSCs [39]. However, the basal plane of graphene is smooth and inert, which is not active for catalytic reactions. In our work [5], We synthesized nitrogen-doped graphene with melamine as nitrogen source via a chemical vapor deposition (CVD) reaction (Figure 30a). Highly-curved GHBs with a 3D hollow nanoball structure can prevent self-assembly restacking in graphene and can provide high surface areas for electrocatalytic reactions. The heteroatomic incorporation enhances the catalytic activities and the electron transfer from $\mathrm{N}$-doped active sites to the adsorbed $\mathrm{I}_{3}{ }^{-}$in the redox reaction of the electrolyte (Figure $30 \mathrm{~b}, \mathrm{c}$ ). It was found that the contents of pyridinic $\mathrm{N}$ and quaternary $\mathrm{N}$ in $\mathrm{N}-\mathrm{GHBs} / \mathrm{CC}$ CEs play a crucial role in the catalytic activity of DSSCs. With a clear understanding of the role of different $\mathrm{N}$-doped states in graphene, people can easily develop a gadget to design highly efficient electrocatalysts for DSSCs. Finally, the photovoltaic performance of the as-prepared N-GHBs with an $\mathrm{N}$-doping content of $12.10 \%$ reached $7.53 \%$ because of the high specific surface area and the decrease of the $R_{\mathrm{ct}}$, which made it very close to that $(7.70 \%)$ of the standard sputtered Pt CEs (Figure 31).

(a)

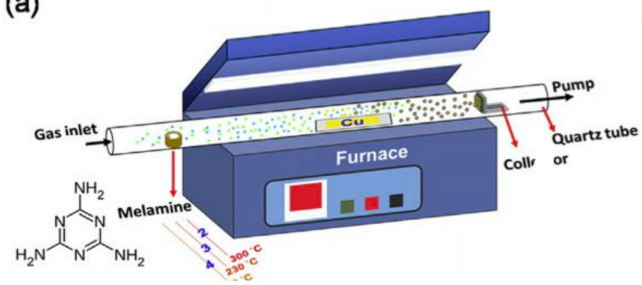

(b)

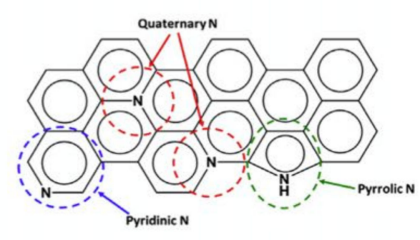

(c)

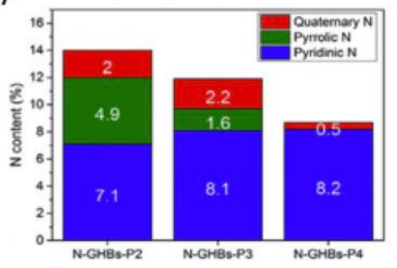

Figure 30. (a) A schematic diagram of the CVD design for the growth of N-GHBs. (b) Three types of N-GHBs, including pyridinic N, pyrrolic N, and quaternary N. (c) The distribution of various N-doped states in different N-GHBs samples [5]. CVD: chemical vapor deposition; N-GHBs: nitrogen-doped graphene hollow nanoballs.

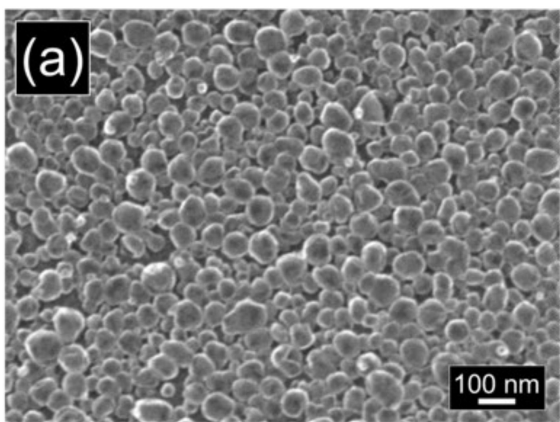

(c)

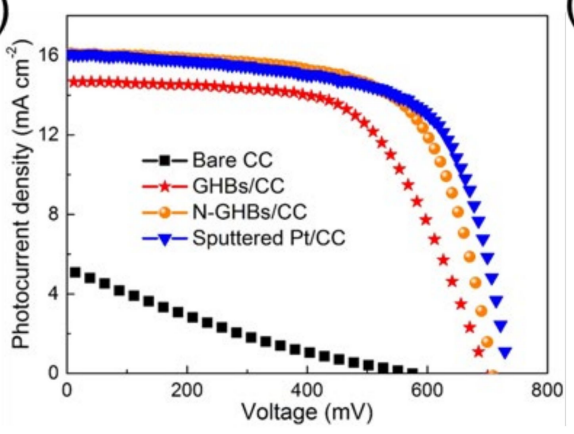

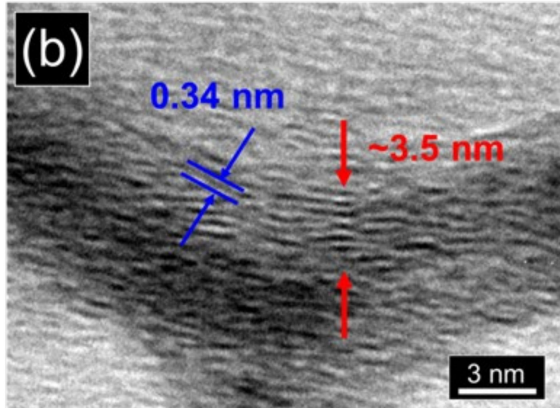

(d)

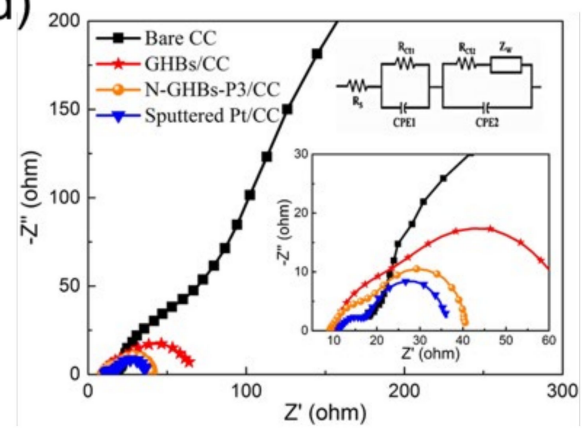

Figure 31. (a) The SEM images and (b) HRTEM image of N-GHBs; (c) Photocurrent density-voltage curves; and (d) EIS measurements of various electrodes [5]. SEM: scanning electron microscope; HRTEM: high resolution transmission electron microscope; N-GHBs: nitrogen-doped graphene hollow nanoballs; EIS: electrochemical impedance spectroscopy. 


\section{Conclusions}

In this short review, we focused on the most recent progress related to low-dimensional electrocatalysts for electrochemical energy applications. Although $\mathrm{Pt}$ is a promising electrocatalyst for hydrogen evolution reactions and triiodide reduction reactions in DSSCs, its precious cost and poor stability reveal the difficulty of using it for practical applications. The development of an alternative to the Pt electrode with a high electrocatalytic activity and good stability is in high demand. GQDs with a good conductivity and high electrocatalytic activity on their edges have been shown to be good candidates as CEs for the triiodide reduction in DSSCs. By incorporating GQDs, the sheet resistance of $\mathrm{CEs}$ and the charge transfer resistance at the $\mathrm{CE} /$ electrolyte interface can be improved. Moreover, the use of 1D materials such as nanowires, nanotubes, and nanoneedles with fast charge transporting properties is attractive to energy conversion applications. Some reports have revealed that $1 \mathrm{D}$ nanostructures can change the hydrophilicity of the material surface and that the robust nanostructures can improve the stability of the hydrogen evolution reaction. Last but not least, 2D TMDCs with a low cost, earth abundance, high activity, and great stability have attracted much attention in recent years. 2D TMDCs have been investigated as potential materials to replace $\mathrm{Pt}$ as electrocatalysts. Studies have shown that 2D materials, such as $\mathrm{MoS}_{2}, \mathrm{WSe}_{2}$, etc., show an electrocatalytic activity that is comparable to that of a standard Pt electrode. For the future development of low-dimensional electrocatalysts with a superior electrocatalytic performance, we may try to synthesize a hierarchically composite matrix consisting of QD, 1D, and 2D nanostructures. Here, the vertically-aligned $1 \mathrm{D}$ electrocatalyst arrays can first be constructed on the electrode substrate, and then the leaf-like 2D electrocatalysts are directly synthesized on the side-wall of the vertically-aligned 1D electrocatalyst; finally, QD electrocatalysts are further used to decorate the basal plane of the 2D electrocatalysts. This design concept aims to solve the general challenges of using the abovementioned low-dimensional electrocatalysts alone, e.g., the aggregation and non-directional charge transport route of QD electrocatalysts; the poor activity on the basal plane of the 2D electrocatalysts and their restacking; and the lower surface area of the vertically-aligned 1D electrocatalyst as compared to QDs within a fixed film thickness. Accordingly, the as-designed composite matrix is expected to achieve a much higher electrocatalytic performance.

Author Contributions: Conceptualization and organization, C.-P.L. and C.-A.T.; Writing-Original draft, H.-Y.C., Y.-H.X. and L.-J.C. All authors have read and agreed to the published version of the manuscript.

Funding: This research received funding from Ministry of Science and Technology (MOST) of Taiwan.

Acknowledgments: This work was supported by the Ministry of Science and Technology (MOST) of Taiwan, under grant numbers 107-2113-M-845-001-MY3.

Conflicts of Interest: The authors declare no conflict of interest.

\section{References}

1. Mas-Ballesté, R.; Gómez-Navarro, C.; Gomez-Herrero, J.; Zamora, F. 2D materials: To graphene and beyond. Nanoscale 2011, 3, 20-30. [CrossRef]

2. Syama, S.; Mohanan, P.V. Comprehensive Application of Graphene: Emphasis on Biomedical Concerns; Springer: Berlin/Heidelberg, Germany, 2019; Volume 11.

3. Wang, C.C.; Lu, S.Y. Carbon black-derived graphene quantum dots composited with carbon aerogel as a highly efficient and stable reduction catalyst for the iodide/tri-iodide couple. Nanoscale 2015, 7, 1209-1215. [CrossRef] [PubMed]

4. Maity, N.; Kuila, A.; Das, S.; Mandal, D.; Shit, A.; Nandi, A.K. Optoelectronic and photovoltaic properties of graphene quantum dot-polyaniline nanostructures. J. Mater. Chem. A 2015, 3, 20736-20748. [CrossRef]

5. Tseng, C.A.; Lee, C.P.; Huang, Y.J.; Pang, H.W.; Ho, K.C.; Chen, Y.T. One-step synthesis of graphene hollow nanoballs with various nitrogen-doped states for electrocatalysis in dye-sensitized solar cells. Mater. Today Energy 2018, 8, 15-21. [CrossRef]

6. Nethravathi, C.; Jeffery, A.A.; Rajamathi, M.; Kawamoto, N.; Tenne, R.; Golberg, D.; Bando, Y. Chemical Unzipping of $\mathrm{WS}_{2}$ Nanotubes. ACS Nano 2013, 7, 7311-7317. [CrossRef] 
7. Ghorbani-Asl, M.; Zibouche, N.; Wahiduzzaman, M.; Oliveira, A.F.; Kuc, A.; Heine, T. Electromechanics in $\mathrm{MoS}_{2}$ and $\mathrm{WS}_{2}$ : Nanotubes vs. monolayers. Sci. Rep. 2013, 3, 2961. [CrossRef]

8. Levi, R.; Bitton, O.; Leitus, G.; Tenne, R.; Joselevich, E. Field-Effect Transistors Based on $\mathrm{WS}_{2}$ Nanotubes with High Current-Carrying Capacity. Nano Lett. 2013, 13, 3736-3741. [CrossRef]

9. Chen, Z.; Duan, X.; Wei, W.; Wang, S.; Ni, B.J. Recent advances in transition metal-based electrocatalysts for alkaline hydrogen evolution. J. Mater. Chem. A 2019, 7, 14971-15005. [CrossRef]

10. Kong, D.; Cha, J.J.; Wang, H.; Lee, H.R.; Cui, Y. First-row transition metal dichalcogenide catalysts for hydrogen evolution reaction. Energy Environ. Sci. 2013, 6, 3553-3558. [CrossRef]

11. Seh, Z.W.; Kibsgaard, J.; Dickens, C.F.; Chorkendorff, I.; Nørskov, J.K.; Jaramillo, T.F. Combining theory and experiment in electrocatalysis: Insights into materials design. Science 2017, 355, 4998. [CrossRef]

12. Sun, Y.; Wang, D.; Shuai, Z. Indirect-to-Direct Band Gap Crossover in Few-Layer Transition Metal Dichalcogenides: A Theoretical Prediction. J. Phys. Chem. C 2016, 120, 21866-21870. [CrossRef]

13. Li, C.; Cao, Q.; Wang, F.; Xiao, Y.; Li, Y.; Delaunay, J.J.; Zhu, H. Engineering graphene and TMDs based van der Waals heterostructures for photovoltaic and photoelectrochemical solar energy conversion. Chem. Soc. Rev. 2018, 47, 4981-5037. [CrossRef] [PubMed]

14. Choi, W.; Choudhary, N.; Han, G.H.; Park, J.; Akinwande, D.; Lee, Y.H. Recent development of two-dimensional transition metal dichalcogenides and their applications. Mater. Today 2017, 20, 116-130. [CrossRef]

15. Chen, L.; Guo, C.; Zhang, Q.; Lei, Y.; Xie, J.; Ee, S.; Guai, G.; Song, Q.; Li, C.M. Graphene Quantum-Dot-Doped Polypyrrole Counter Electrode for High-Performance Dye-Sensitized Solar Cells. ACS Appl. Mater. Interfaces 2013, 5, 2047-2052. [CrossRef]

16. Saranya, K.; Sivasankar, N.; Subramania, A. Microwave-assisted exfoliation method to develop platinum-decorated graphene nanosheets as a low cost counter electrode for dye-sensitized solar cells. RSC Adv. 2014, 4, 36226-36233. [CrossRef]

17. Liu, T.; Yu, K.; Gao, L.; Chen, H.; Wang, N.; Hao, L.; Li, T.; He, H.; Guo, Z. A graphene quantum dot decorated $\mathrm{SrRuO3mesoporous} \mathrm{film} \mathrm{as} \mathrm{an} \mathrm{efficient} \mathrm{counter} \mathrm{electrode} \mathrm{for} \mathrm{high-performance} \mathrm{dye-sensitized} \mathrm{solar} \mathrm{cells.}$ J. Mater. Chem. A 2017, 5, 17848-17855. [CrossRef]

18. Gupta, V.; Chaudhary, N.; Srivastava, R.; Sharma, G.D.; Bhardwaj, R.; Chand, S. Luminscent Graphene Quantum Dots for Organic Photovoltaic Devices. J. Am. Chem. Soc. 2011, 133, 9960-9963. [CrossRef]

19. Yue, G.; Wu, J.; Xiao, Y.; Lin, J.; Huang, M. Low cost poly(3,4-ethylenedioxythiophene): Polystyrenesulfonate/ carbon black counter electrode for dye-sensitized solar cells. Electrochim. Acta 2012, 67, 113-118. [CrossRef]

20. Lee, C.P.; Lin, C.A.; Wei, T.C.; Tsai, M.L.; Meng, Y.; Li, C.T.; Ho, K.C.; Wu, C.I.; Lau, S.P.; He, J.H. Economical low-light photovoltaics by using the Pt-free dye-sensitized solar cell with graphene dot/PEDOT: PSS counter electrodes. Nano Energy 2015, 18, 109-117. [CrossRef]

21. Mohanty, B.; Ghorbani-Asl, M.; Kretschmer, S.; Ghosh, A.; Guha, P.; Panda, S.K.; Jena, B.; Krasheninnikov, A.V.; Jena, B.K. $\mathrm{MoS}_{2}$ Quantum Dots as Efficient Catalyst Materials for the Oxygen Evolution Reaction. ACS Catal. 2018, 8, 1683-1689. [CrossRef]

22. Qiao, W.; Yan, S.; Song, X.; Zhang, X.; Sun, Y.; Chen, X.; Zhong, W.; Du, Y. Monolayer MoS 2 quantum dots as catalysts for efficient hydrogen evolution. RSC Adv. 2015, 5, 97696-97701. [CrossRef]

23. Chen, Z.; Cummins, D.; Reinecke, B.N.; Clark, E.L.; Sunkara, M.K.; Jaramillo, T.F. Core-shell $\mathrm{MoO}_{3}-\mathrm{MoS}_{2}$ Nanowires for Hydrogen Evolution: A Functional Design for Electrocatalytic Materials. Nano Lett. 2011, 11, 4168-4175. [CrossRef] [PubMed]

24. Qu, Y.; Yang, M.; Chai, J.; Tang, Z.; Shao, M.; Kwok, C.T.; Yang, M.; Wang, Z.; Chua, D.; Wang, S.; et al. Facile Synthesis of Vanadium-Doped $\mathrm{Ni}_{3} \mathrm{~S}_{2}$ Nanowire Arrays as Active Electrocatalyst for Hydrogen. ACS Appl. Mater. Interfaces 2017, 9, 5959-5967. [CrossRef]

25. Zhang, J.; Wang, T.; Pohl, D.; Rellinghaus, B.; Dong, R.; Liu, S.; Zhuang, X.D.; Feng, X. Interface Engineering of $\mathrm{MoS}_{2} / \mathrm{Ni}_{3} \mathrm{~S}_{2}$ Heterostructures for Highly Enhanced Electrochemical Overall-Water-Splitting Activity. Angew. Chem. Int. Ed. 2016, 55, 6702-6707. [CrossRef] [PubMed]

26. Wu, Y.; Li, G.D.; Liu, Y.; Yang, L.; Lian, X.; Asefac, T.; Zou, X. Overall Water Splitting Catalyzed Efficiently by an Ultrathin Nanosheet-Built, Hollow $\mathrm{Ni}_{3} \mathrm{~S}_{2}$-Based Electrocatalyst. Adv. Funct. Mater. 2016, 26, 4839-4847. [CrossRef]

27. Xu, K.; Wang, F.; Wang, Z.; Zhan, X.; Wang, Q.; Cheng, Z.; Safdar, M.; He, J. Component-Controllable $\mathrm{WS}_{2(1-\mathrm{x})} \mathrm{Se}_{2 \mathrm{x}}$ Nanotubes for Efficient Hydrogen Evolution Reaction. ACS Nano 2014, 8, 8468-8476. [CrossRef] 
28. Xie, J.; Zhang, H.; Li, S.; Wang, R.; Sun, X.; Zhou, M.; Zhou, J.; Lou, X.W.; Xie, Y. Defect-Rich MoS 2 Ultrathin Nanosheets with Additional Active Edge Sites for Enhanced Electrocatalytic Hydrogen Evolution. Adv. Mater. 2013, 25, 5807-5813. [CrossRef]

29. Gong, Y.; Liu, Z.; Lupini, A.R.; Shi, G.; Lin, J.; Najmaei, S.; Lin, Z.; Elías, A.L.; Berkdemir, A.; You, G.; et al. Band Gap Engineering and Layer-by-Layer Mapping of Selenium-Doped Molybdenum Disulfide. Nano Lett. 2013, 14, 442-449. [CrossRef]

30. Phuruangrat, A.; Ham, D.J.; Hong, S.J.; Thongtem, S.; Lee, J.S. Synthesis of hexagonal $\mathrm{WO}_{3}$ nanowires by microwave-assisted hydrothermal method and their electrocatalytic activities for hydrogen evolution reaction. J. Mater. Chem. 2010, 20, 1683-1690. [CrossRef]

31. Zibouche, N.; Ghorbani-Asl, M.; Heine, T.; Kuc, A. Electromechanical Properties of Small Transition-Metal Dichalcogenide Nanotubes. Inorganics 2014, 2, 155-167. [CrossRef]

32. Xie, J.; Zhang, J.; Li, S.; Grote, F.; Zhang, X.; Zhang, H.; Wang, R.; Lei, Y.; Pan, B.C.; Xie, Y. Controllable Disorder Engineering in Oxygen-Incorporated $\mathrm{MoS}_{2}$ Ultrathin Nanosheets for Efficient Hydrogen Evolution. J. Am. Chem. Soc. 2013, 135, 17881-17888. [CrossRef] [PubMed]

33. Lee, C.P.; Chen, W.F.; Billo, T.; Lin, Y.G.; Fu, F.Y.; Samireddi, S.; Lee, C.H.; Hwang, J.S.; Chen, L.C.; Chen, L.-C. Beaded stream-like $\mathrm{CoSe}_{2}$ nanoneedle array for efficient hydrogen evolution electrocatalysis. J. Mater. Chem. A 2016, 4, 4553-4561. [CrossRef]

34. Kong, D.; Wang, H.; Lu, Z.; Cui, Y. CoSe 2 Nanoparticles Grown on Carbon Fiber Paper: An Efficient and Stable Electrocatalyst for Hydrogen Evolution Reaction. J. Am. Chem. Soc. 2014, 136, 4897-4900. [CrossRef]

35. Faber, M.S.; Lukowski, M.A.; Ding, Q.; Kaiser, N.S.; Jin, S. Earth-Abundant Metal Pyrites $\left(\mathrm{FeS}_{2}, \mathrm{CoS}_{2}, \mathrm{NiS}_{2}\right.$, and Their Alloys) for Highly Efficient Hydrogen Evolution and Polysulfide Reduction Electrocatalysis. J. Phys. Chem. C 2014, 118, 21347-21356. [CrossRef]

36. Mak, K.F.; Lee, C.; Hone, J.; Shan, J.; Heinz, T.F. Atomically Thin $\mathrm{MoS}_{2}$ : A New Direct-Gap Semiconductor. Phys. Rev. Lett. 2010, 105, 136805. [CrossRef]

37. Yue, G.; Lin, J.Y.; Tai, S.Y.; Xiao, Y.; Lan, Z. A catalytic composite film of $\mathrm{MoS}_{2} /$ graphene flake as a counter electrode for Pt-free dye-sensitized solar cells. Electrochim. Acta 2012, 85, 162-168. [CrossRef]

38. Fan, M.S.; Lee, C.P.; Li, C.T.; Huang, Y.J.; Vittal, R.; Ho, K.C. Nitrogen-doped graphene/molybdenum disulfide composite as the electrocatalytic film for dye-sensitized solar cells. Electrochim. Acta 2016, 211, 164-172. [CrossRef]

39. Chang, Y.C.; Tseng, C.A.; Lee, C.P.; Ann, S.B.; Huang, Y.J.; Ho, K.C.; Chen, Y.T. N- and S-codoped graphene hollow nanoballs as an efficient Pt-free electrocatalyst for dye-sensitized solar cells. J. Power Sources 2020, 449, 227470. [CrossRef]

40. Jamil, A.; Batool, S.S.; Sher, F.; Rafiq, M.A. Determination of density of states, conduction mechanisms and dielectric properties of nickel disulfide nanoparticles. AIP Adv. 2016, 6, 55120. [CrossRef]

41. Yang, S.; Yao, H.B.; Gao, M.R.; Yu, S.H. Monodisperse cubic pyrite NiS2 dodecahedrons and microspheres synthesized by a solvothermal process in a mixed solvent: Thermal stability and magnetic properties. CrystEngComm 2009, 11, 1383-1390. [CrossRef]

42. Singh, E.; Kim, K.S.; Yeom, G.Y.; Nalwa, H.S. Two-dimensional transition metal dichalcogenide-based counter electrodes for dye-sensitized solar cells. RSC Adv. 2017, 7, 28234-28290. [CrossRef]

43. Li, Z.; Gong, F.; Zhou, G.; Wang, Z.S. NiS 2 /Reduced Graphene Oxide Nanocomposites for Efficient Dye-Sensitized Solar Cells. J. Phys. Chem. C 2013, 117, 6561-6566. [CrossRef]

44. Gao, J.; Cheng, Y.; Tian, T.; Hu, X.; Zeng, K.; Zhang, Y.W.; Zhang, Y.W. Structure, Stability, and Kinetics of Vacancy Defects in Monolayer PtSe 2 : A First-Principles Study. ACS Omega 2017, 2, 8640-8648. [CrossRef] [PubMed]

45. Miro, P.; Heine, T.; Ghorbani-Asl, M. Two Dimensional Materials beyond $\mathrm{MoS}_{2}$ : Noble-Transition-Metal Dichalcogenides. Angew. Chem. Int. Ed. 2014, 53, 3015-3018. [CrossRef]

46. Hussain, S.; Patil, S.A.; Vikraman, D.; Arbab, A.A.; Jeong, S.H.; Kim, H.S.; Choi, H. Growth of a WSe $2 /$ W counter electrode by sputtering and selenization annealing for high-efficiency dye-sensitized solar cells. Appl. Surf. Sci. 2017, 406, 84-90. [CrossRef]

(C) 2020 by the authors. Licensee MDPI, Basel, Switzerland. This article is an open access article distributed under the terms and conditions of the Creative Commons Attribution (CC BY) license (http://creativecommons.org/licenses/by/4.0/). 